\title{
Acute Toxicity of Double-Walled Carbon Nanotubes to Three Aquatic Organisms
}

\author{
Lungile P. Lukhele, ${ }^{1,2}$ Bhekie B. Mamba, ${ }^{3}$ Ndeke Musee, ${ }^{4}$ and Victor Wepener ${ }^{5}$ \\ ${ }^{1}$ Department of Applied Chemistry, University of Johannesburg, P.O. Box 17011, Doornfontein, Johannesburg 2028, South Africa \\ ${ }^{2}$ Department of Zoology, University of Johannesburg, P.O. Box 534, Auckland Park 2006, South Africa \\ ${ }^{3}$ Nanotechnology and Water Sustainability Research Unit, College of Engineering, Science and Technology, \\ University of South Africa Florida Campus, Roodepoort 1709, South Africa \\ ${ }^{4}$ Nanotechnology Sustainability Research Group, Natural Resources and the Environment, CSIR, P.O. Box 395, Pretoria 0001, South \\ Africa \\ ${ }^{5}$ Unit for Environmental Sciences and Management, North West University, Private Bag X6001, Potchefstroom 2520, South Africa
}

Correspondence should be addressed to Lungile P. Lukhele; lungi606@gmail.com

Received 6 November 2014; Revised 8 January 2015; Accepted 12 January 2015

Academic Editor: Biswarup Sen

Copyright ( 2015 Lungile P. Lukhele et al. This is an open access article distributed under the Creative Commons Attribution License, which permits unrestricted use, distribution, and reproduction in any medium, provided the original work is properly cited.

\begin{abstract}
This study investigated the toxicity of double walled carbon nanotubes (DWCNTs) to three aquatic organisms, namely, Pseudokirchneriella subcapitata, Daphnia pulex, and Poecilia reticulata under the influence of exposure media properties specifically the ionic strength and organic matter represented by humic acid. Results indicated that ionic strength enhanced DWCNTs agglomeration whilst humic acid stabilized the CNTs and in turn inhibited the formation of aggregates. $\mathrm{LC}_{50} \mathrm{~s}$ for $D$. pulex were higher at 2.81 and $4.45 \mathrm{mg} / \mathrm{L}$ for pristine and oxidised DWCNTs, respectively; however, P. reticulata had lower values of $113.64 \mathrm{mg} / \mathrm{L}$ and $214.0 \mathrm{mg} / \mathrm{L}$ for the same CNTs correspondingly. P. subcapitata had $\mathrm{EC}_{50}$ s of $17.95 \mathrm{mg} / \mathrm{L}$ and $10.93 \mathrm{mg} / \mathrm{L}$ for the pristine and oxidised DWCNTs, respectively. In the presence of humic acid high DWCNTs acute toxicity towards D. pulex and P. reticulata was observed but ionic strength led to opposite effect irrespective of DWCNTs form. Both humic acid and ionic strength shielded the P. subcapitata from toxic effects of DWCNTs. Overall, our findings suggest that the toxicity of DWCNTs in the aquatic systems (i) will be dependent on media properties and (ii) is likely to proceed at different rates to organisms at different trophic levels.
\end{abstract}

\section{Introduction}

Carbon nanotubes (CNTs) are the most widely studied class of engineered nanomaterials. This is due to carbon's unique hybridisation properties and the sensitivity to variations in the synthesis conditions allowing tailoring of these nanostructures for specific applications [1]. The science and applicability of CNTs are well understood and that is the main reason why they are quite popular. CNTs vary by the number of graphitic layers in their side walls. The types that have been extensively studied and are commercially available are singlewalled carbon nanotubes (SWCNTs), double-walled carbon nanotubes (DWCNTs), and multiwalled carbon nanotubes (MWCNTs) $[2,3]$. Double-walled carbon nanotubes (DWCNTs) have attracted much attention in recent years because they are an excellent compromise between SWNTs and
MWNTs [4]. This is because it is possible to functionalise the outer wall to ensure interaction with its external environment while retaining the unique properties of the inner carbon nanotube. Chemical and physical properties of DWCNTs are similar to those of SWNTs $[4,5]$.

The synthesis and use of CNTs lead to their release into the environment, particularly the aquatic environment. This may be as a result of the use of CNTs and through wastewater containing nanowaste and runoff from landfills [6]. Hence data on the fate and behaviour of CNTs in different types of natural water systems as well as their potential ecotoxicity is essential for the quantitative assessment of environmental risks of nanomaterials [7]. Generally, the development, production, use, and disposal of new technologies have been found to cause a significant impact on the environmental dimension of sustainable development [8]. 
Hence, proactive investigation on the impact of CNTs in the aquatic environment merits urgent attention. This is because the sustainability of a given technology, from an economical, sociological, environmental, and governance perspective, is dependent on the understanding of its impacts on humans and other biological life forms in the environment [9].

Aquatic toxicology has been identified as a useful tool for assessing environmental risks associated with CNTs [10]. Acute toxicity is the most fundamental of toxicological investigations. It is routinely performed as a regulatory requirement for different substances such as chemicals and wastewater effluents [10]. The results of these tests are used to determine the hazard that may be caused by the tested substance and wastewater effluents [11, 12]. Acute toxicity results also inform the experimental design for subsequent sublethal toxicity investigations [13]. Research on nanoecotoxicology has focused on estimating lethal concentrations, evaluating sublethal effects on organisms, and identifying mechanisms of toxicity on ENMs [7]. The focus has been on biological endpoints at population level such as growth, reproduction, and mortality [11]. Like chemicals, ENMs trigger several of the fundamental toxicity responses. The quantitative toxicity data such as $\mathrm{EC}_{50}$ are essential in the estimation of a precise dose-response relationship between organisms and test material [14-16].

The aquatic ecotoxicity of ENMs is greatly influenced by their speciation in aquatic environments $[17,18]$. The stability or agglomeration of ENMs in aquatic environments is mainly governed by particle characteristics and physicochemical parameters of water such as ionic strength, $\mathrm{pH}$, and dissolved organic matter $[19,20]$. The physicochemical parameters alter the colloidal behaviour of nanoparticles which then has a direct bearing on the nanoparticle-organism interaction in aquatic environments. The change in nanoparticle-organism interactions has been reported to impact the toxicity of ENMs $[20,21]$. Hence, it is important to examine the effect of physicochemical parameters on the acute toxicity of ENMs to aquatic organisms.

This study reports the influence of ionic strength (based on $\mathrm{Na}$ and $\mathrm{Ca}$ ) and humic acid on the acute toxicity of pristine and oxidised DWCNTs to three aquatic organisms representing three different trophic levels, that is, primary consumers (algae), P. subcapitata; macroinvertebrates, D. pulex; and fish, $P$. reticulata. These organisms form part of standard toxicity testing guidelines such as those issued by the OECD and USEPA $[10,11]$.

\section{Materials and Methods}

Double-walled carbon nanotubes were synthesised in our laboratories using the catalytic vapour deposition method as described by Flahaut and coworkers [6]. The DWCNTs were oxidised by refluxing the DWCNTs in nitric acid at $55^{\circ} \mathrm{C}$ for $3 \mathrm{~h}$.

2.1. Characterisation of DWCNTs. Surface morphology and DWCNT diameter were determined using high resolution transmission electron microscopy (HR TEM, JEOL Jem2100) and scanning electron microscopy (SEM, JEOL JSM
7500F coupled with EDX). Elemental composition of DWCNTs was determined using energy dispersive X-ray spectroscopy (EDX) and surface functionality was determined using Raman spectroscopy (Perkin Elmer Raman Microscope, RamanMicro 200) and Fourier transform infrared spectroscopy (Perkin Elmer Spectrum 100 FT-IR-spectrometer). Hydrodynamic size and zeta potential in aqueous DWCNT suspensions were determined using dynamic light scattering (Malvern Zetasizer Nano series, NanoZS).

\subsection{Preparation of Stock Suspensions and \\ Their Characterisation}

2.2.1. Preparation of DWCNT Suspensions of Varying Ionic Strengths $\left(\mathrm{Ca}^{2+}\right)$. Moderately hard reconstituted waters with varying ionic $\mathrm{Ca}^{2+}$ strengths were prepared by varying the amount of calcium carbonate. Reconstituted waters with ionic strengths of $0.00449 \mathrm{M} \mathrm{Ca}^{2+}, 0.0226 \mathrm{M} \mathrm{Ca}^{2+}$, and $0.0339 \mathrm{M} \mathrm{Ca}^{2+}$ were prepared. The salts used to prepare reconstituted water were kept constant when $\mathrm{Ca}^{2+}$ was varied. The salts were $0.2400 \mathrm{~g}$ of $\mathrm{NaHCO}_{3}, 0.0200 \mathrm{~g}$ of KCL, and $0.1500 \mathrm{~g}$ of $\mathrm{MgSO}_{4}$ and these were added to $5 \mathrm{~L}$ of Milli-Q water. The DWCNT suspensions were prepared by adding $50 \mathrm{mg}$ of DWCNTs to $100 \mathrm{~mL}$ of the prepared waters with varying ionic strengths. The suspensions were sonicated for $2 \mathrm{~h}$ and were shaken at $30 \mathrm{~min}$ intervals. The suspensions were then refrigerated at $4^{\circ} \mathrm{C}$ for $24 \mathrm{~h}$.

2.2.2. Preparation of DWCNT Suspensions at Varying Humic Acid Concentrations. A stock solution of humic acid was prepared by dissolving $50 \mathrm{mg}$ of humic acid powder containing $20 \%$ ash (Fluka) in $100 \mathrm{~mL}$ of Milli-Q water. The humic acid powder contained ash estimated to be $20 \%$ of the mass of the powder. It was important to first eliminate the ash content from the solution and determine the exact concentration of humic acid in the stock solution. The solution was filtered with a $0.45 \mu \mathrm{m}$ filter paper under vacuum. A series of standards were prepared using the stock solution and were analysed using a Cary UV 50 scan UV spectroscopy and the dissolved carbon was analysed using a total organic carbon analyser. A calibration curve was plotted to obtain an equation that was used to calculate the TOC value of the stock solution using readings at $254 \mathrm{~nm}$. The dissolved organic carbon was determined using the Tekmar Apollo 9000 total organic carbon (TOC) analyser.

2.2.3. Preparation of DWCNT Suspensions at Varying Ionic Strengths $\left(\mathrm{Na}^{+}\right)$. Double-walled carbon nanotubes stock suspensions were prepared by adding $5 \mathrm{mg}$ of carbon nanotubes (pristine and oxidised) to $100 \mathrm{~mL}$ of Milli-Q water ( $\mathrm{pH} \mathrm{7).}$ Sodium chloride was added to the DWCNT suspension to vary the ionic strength in suspensions from 0.00335 , $0.00585,0.00835$, and $0.0139 \mathrm{M} \mathrm{NaCl}$. The suspensions were then sonicated for $2 \mathrm{~h}$ and refrigerated at $4^{\circ} \mathrm{C}$ for $24 \mathrm{~h}$ (to stabilise the suspensions).

The hydrodynamic particle size was determined and zeta potential measurements were done for each of the different 
salinity and humic acid conditions using dynamic light scattering.

\subsection{Bioassays}

2.3.1. Pseudokirchneriella subcapitata Growth Inhibition Test. The algal toxicity tests were carried out using the Algaltoxkit sourced from MicroBioTests Inc. (Cat. \# 030229). The test kit contained prepared nutrient stock solutions for the culturing medium, matrix dissolving medium, algal beads, and plastic long cells. In our tests, the long cells were replaced with glass Erlenmeyer flasks.

Algal culturing medium ( $2 \mathrm{~L}$ ) was prepared by adding $20 \mathrm{~mL}$ of nutrient stock solution A and adding $2 \mathrm{~mL}$ (each) of nutrient stock solutions B, C, and D. The medium was aerated and set aside. The P. subcapitata culture was prepared by first dissolving the alginate matrix (used to form the beads) in matrix dissolving medium in order to recover viable and cultivable cells and thereafter rinsing the cells in culture medium 3 times. The algal culture was resuspended in $25 \mathrm{~mL}$ of culture medium. The cell density was determined using a spectrophotometer and was confirmed using manual cell counting.

The DWCNT stock solution was prepared by mixing $10 \mathrm{mg}$ of dry DWCNT and $100 \mathrm{~mL}$ of culture medium in $100 \mathrm{~mL}$ Schott bottles. The mixture was then sonicated for $2 \mathrm{~h}$ in an ultrasonication bath. The suspensions were prepared $24 \mathrm{~h}$ before toxicity tests were carried out and were refrigerated at $4^{\circ} \mathrm{C}$.

A total of six exposure concentrations arranged in a geometric series with a separation factor of 2 were prepared, with the highest DWCNT concentration being $100 \mathrm{mg} / \mathrm{L}$. The diluted DWCNT suspensions ( $25 \mathrm{~mL}$ in each flask) were placed in Erlenmeyer flasks. A total of 10000 algal cells (volume of stock solution added was calculated using the cell density in stock solution) were added to each Erlenmeyer flask. Each DWCNT concentration was prepared in duplicate. Controls consisting of duplicate negative (i.e., no DWCNTs added) and positive (reference toxicant $\mathrm{CdCl}_{2}, 100 \mathrm{mg} / \mathrm{L}$ ) were included in each bioassay. The algae were incubated for a period of $96 \mathrm{~h}$ in an incubator under a 16:8 h, light: dark regime.

Two samples $(0.5 \mathrm{~mL})$ from each Erlenmeyer flask were collected at $24 \mathrm{~h}$ intervals. Algal cell densities in samples were determined by cell counting using a haemocytometer chamber under a light microscope. Calculations of growth inhibition were done according to the OECD guidelines [22].

Algae cells were counted using a haemocytometer chamber with at least two counts for each replicate. Manual cell counting was required because the determination of cell density by UV/Vis absorption was not possible due to the large variations in the background spectrum of the test suspensions containing CNT. The lack of quicker, less laborious, and validated methods to quantify green algae in the presence of CNT and particulate matter in general has made manual cell counting the only option.

2.3.2. Daphnia (Invertebrate) Immobilisation Test. Test organisms, Daphnia pulex, were sourced from in-house cultures maintained in the aquarium at the University of Johannesburg. Daphnia pulex was cultured in a temperature controlled room at $22 \pm 2^{\circ} \mathrm{C}$ under $14 \mathrm{hr}$ illumination. The daphnids were cultured in moderately hard synthetic water and were fed dried yeast. The $D$. pulex bioassay was conducted in a $25 \mathrm{~mL}$ volume using $60 \mathrm{~mL}$ glass beakers under static nonrenewal conditions for $48 \mathrm{~h}$. A total of five neonates were exposed to test solution with three replicates per concentration. Exposure solutions were prepared from a DWCNT stock solution and moderately hard reconstituted water was used as a medium for the test [23]. DWCNT concentrations arranged in a geometric series with a separation factor of 1.5 were prepared, with the highest DWCNT concentration being $10 \mathrm{mg} / \mathrm{L}$. The number of mortalities was recorded at $24 \mathrm{~h}$ intervals for the duration of the study period. Dead organisms were gently removed from the exposure vessel using a Pasteur pipette. Following exposure, the surviving organisms in each beaker were collected for microscopic analysis.

2.3.3. Poecilia reticulata (Fish) Acute Toxicity Test. Fish were sourced from Kirsten Aquaculture, situated at Modimolle, South Africa. The age of the fish used for exposure experiments ranged from $10 \mathrm{~d}$ to $21 \mathrm{~d}$. The fish were exposed for $96 \mathrm{~h}$ to different DWCNT concentrations $(500 \mathrm{mg} / \mathrm{L}, 250 \mathrm{mg} / \mathrm{L}$, $125 \mathrm{mg} / \mathrm{L}, 62.5 \mathrm{mg} / \mathrm{L}, 31.25 \mathrm{mg} / \mathrm{L}$, and $15.6 \mathrm{mg} / \mathrm{L}$ ) using the static nonrenewal test. The tests were conducted in $600 \mathrm{~mL}$ low form glass beakers using moderately hard reconstituted water and five fish were placed in each beaker. The exposure tests were done in triplicate, with four negative controls (no DWCNTs added) and four positive controls (reference toxicant, $1000 \mathrm{mg} / \mathrm{L} \mathrm{K}_{2} \mathrm{Cr}_{2} \mathrm{O}_{7}$ ). The experiments and controls were prepared in accordance with the OECD Guidelines 203 (2002) ( $\mathrm{pH} 6$ to 8.5 , dissolved oxygen $>80 \%$, conductivity $<10 \mu \mathrm{S} / \mathrm{cm}$, and temperature $21^{\circ} \mathrm{C}$ to $25^{\circ} \mathrm{C}$ ). Fish mortalities were recorded over the $96 \mathrm{~h}$ period at $24 \mathrm{~h}$ intervals. Dead fish were removed from exposure vessels using a pair of forceps while carefully avoiding the agglomerates surrounding the fish. Abiotic parameters of test solutions were tested before fish were added [24].

2.4. Statistical Analysis. As an estimate of relative lethal toxicity, $\mathrm{EC}_{50} / \mathrm{LC}_{50}$ values were based on the cumulative mortality observed at the end of a desired exposure time. $\mathrm{EC}_{50} / \mathrm{LC}_{50}$ values for each test species together with their respective $95 \%$ confidence intervals (CI) were calculated using the most appropriate statistical method for the specific toxicity data. The USEPA Probit Analysis Program used for calculating LC/EC values (version 1.5) was initially used to calculate the $\mathrm{EC}_{50} / \mathrm{LC}_{50}$ values [25]. When data did not fit the assumptions of the Probit method, the data were then analysed using the Trimmed Spearman-Karber method [26]. To determine whether there were any significant differences between the $\mathrm{EC}_{50} / \mathrm{LC}_{50}$ values for the different DWCNT concentrations and treatments, the following formula was used: $f_{1.2}=\operatorname{antilog} \sqrt{ }\left(\left(\log f_{1}\right)^{2}+\left(\log f_{2}\right)^{2}\right)$, where $f$ is the factor for $95 \%$ confidence limits of the $\mathrm{EC}_{50} / \mathrm{LC}_{50}$ and is calculated by dividing the upper confidence limit by the $\mathrm{EC}_{50} / \mathrm{LC}_{50}$. If the ratio of the higher $\mathrm{EC}_{50} / \mathrm{LC}_{50}$ to the lower $\mathrm{EC}_{50} / \mathrm{LC}_{50}$ exceeds the value of $f_{1.2}$ for both the upper and 
lower $95 \%$ confidence limits, the $\mathrm{EC}_{50} / \mathrm{LC}_{50}$ s are considered to be significantly different [27].

\section{Results and Discussion}

\subsection{Characterisation of DWCNTS}

3.1.1. Surface Morphology. The SEM micrograph of pristine DWCNTs showed a mixture of catalyst residues and some protruding fibre-like structures (Figure 1(a)). The fibre-like structures are DWCNTs surrounded by excess catalyst and some amorphous carbon. After oxidation, a large amount of the residual catalyst and amorphous carbon were removed leaving DWCNTs. However, small amounts of catalyst residue were still visible (Figure 1(b)).

The surface morphology of DWCNTs was analysed using TEM. Figure 2(a) is a TEM image of pristine DWCNTs and they contain some residual catalyst within the DWCNTs and amorphous carbon around the tubes. Some residual catalyst is still present in oxidised DWCNTs (Figure 2(b)). The average diameter of DWCNTs was found to be $3.60 \mathrm{~nm}$ and the majority of CNTs had a diameter range of $2-3 \mathrm{~nm}$ (Figure 2(c)).

3.1.2. Surface Functionalisation. Oxidation of DWCNTs was confirmed by FT-IR spectroscopy. The peak at around 1 $721 \mathrm{~nm}$ is characteristic of the $\mathrm{C}=\mathrm{O}$ group. Some $\mathrm{O}-\mathrm{H}$ groups were identified at the $3492 \mathrm{~nm}$ peak and C-O groups were identified at around $1207 \mathrm{~nm}$ for the oxidised DWCNTs but were insignificant in the case of pristine DWCNTs (Figure 3).

The quality of DWCNTs was determined using Raman spectroscopy. The D-band peak which was observed at approximately $1300 \mathrm{~cm}^{-1}$, for both pristine and oxidised DWCNTs, is related to the presence of defects on the walls of CNTs (Figure 4). The G-band observed at approximately $1600 \mathrm{~cm}^{-1}$ is associated with the in-plane vibrations of graphene sheets. The D-band/G-band ratio is a general indicator of the extent of disorder within CNTs.

3.2. Elemental Composition. Pristine DWCNTs contained a large amount of magnesium and molybdenum which originated from the magnesium oxide supported $\mathrm{Mo} / \mathrm{Co}$ catalyst used for the synthesis of DWCNTs. Some oxygen was also present in pristine DWCNTS (Figure 5(a)).

After oxidation, DWCNTs still contained some of the molybdenum. Magnesium oxide in the catalyst is used as a support for the molybdenum and acid treatment removed most of the magnesium oxide leaving the molybdenum (Figure 5(b)).

The oxygen fundamentally found to be present in DWCNTs is a result of oxidation in the presence of nitric acid. Carbon, as expected, was also detected.

Characteristics such as size distribution, surface chemistry, surface charge, and dispersion in aqueous phase have been identified as essential in studying the environmental fate of DWCNTs. Such data are essential because the interactions of environmental and biological systems are dependent on them [7].
Surface morphology and the presence of impurities in pristine DWCNT were determined by TEM and SEM. Pristine DWCNTs had impurities on their surface while oxidised DWCNTs had very few impurities. Elemental analysis using EDX indicated that pristine DWCNTs contained residual magnesium and molybdenum content originating from the catalyst used during synthesis of DWCNTs. Flahaut and colleagues reported a similar finding of metal residue on DWCNTs and attributed these residues to poor dispersion of the metal catalyst. Some amount of oxygen was also present in as-prepared DWCNTS. The oxygen content originated from a $\mathrm{MoO}_{x}$, a species detected by Flahaut and coworkers through $\mathrm{X}$-ray diffraction [6]. Metal catalyst residues are often very difficult to remove from carbon-based nanoparticles. These metal particles are normally embedded in the tube or particle and their removal involves using harsh acid treatment which can destroy the nanoparticle $[2,7]$.

Oxidation of DWCNTs was confirmed using FT-IR spectroscopy where vibrational peaks of $\mathrm{C}=\mathrm{O}, \mathrm{C}-\mathrm{O}$, and $\mathrm{O}-\mathrm{H}$ bonds were detected in oxidised DWCNTs. From the Raman spectra of pristine and oxidised DWCNTs the $I_{D} / I_{G}$ ratio of pristine DWCNTs was low (between 0.1 and 0.2 ), whereas that of oxidised DWCNTs was approximately 1 . A low $I_{D} / I_{G}$ ratio indicates that the material exhibits high crystallinity while a higher ratio indicates the presence of defects on the surface of DWCNTs confirming the presence of functionalities on the surfaces of DWCNTs [2].

3.3. Effect of Changes in Physicochemical Properties of Water on the Stability of DWCNT Suspensions. Ionic strength (IS) and natural organic matter were found to influence the surface charge on DWCNT surfaces resulting in reduced or increased stability of DWCNTs in water suspensions.

3.3.1. Effect of Ionic Strength. Increasing ionic strength caused an increased aggregation of both pristine and oxidised DWCNTs. The salts used in suspensions to vary ionic strength, $\mathrm{CaCO}_{3}$ and $\mathrm{NaCl}$, had different effects on the colloidal stability of pristine and oxidised DWCNTs.

3.3.2. The Effect of $\mathrm{Na}^{+}$. The addition of sodium chloride in the DWCNTs suspensions resulted in increased aggregation in both pristine and oxidised DWCNTs as the IS was increased (Figure 6). Oxidised DWCNTs had a higher hydrodynamic particle size compared to pristine DWCNTs. Pristine DWCNTs had a slight decrease in particle size at $0.00835 \mathrm{M}$. In subsequent ionic strengths, an increase in particle size was observed.

A decrease in zeta potential for both pristine and oxidised DWCNTs was observed (Figure 6) with the exception of 0.00835 M IS, where there was an increase for both DWCNTs. There was a greater increase for oxidised DWCNTs since oxidised DWCNTs had a lower zeta potential at $0 \mathrm{M}$ but had a higher zeta potential at $0.00835 \mathrm{M}$ when compared to pristine DWCNTs.

The increase in hydrodynamic size in particles is as a result of higher aggregation caused by the increased salinity in water. The presence of electrolytes in water affects the stabilisation of colloids in the aqueous phase thus lowering 

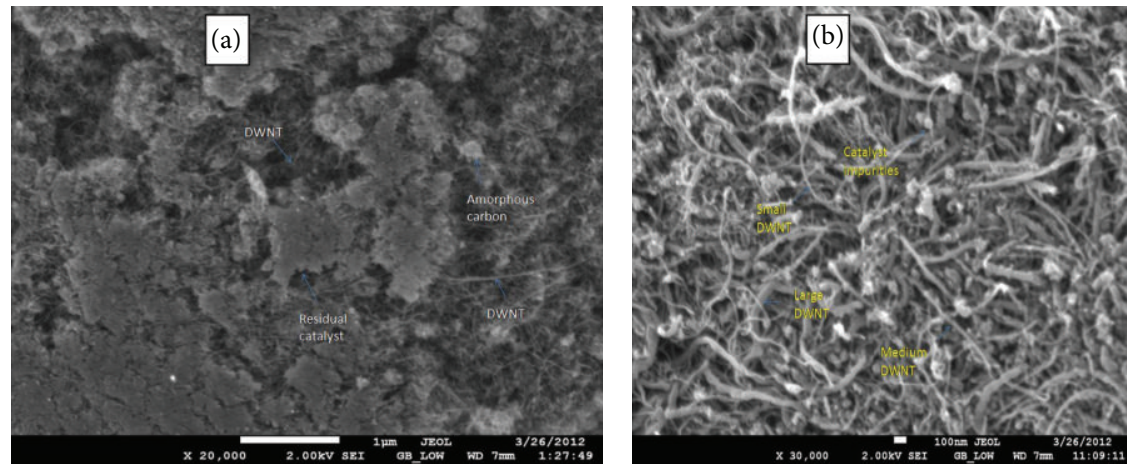

FIGURE 1: (a) SEM micrograph of pristine DWCNTs showing catalyst residues. (b) SEM micrograph of oxidised DWCNTs showing nanotubes of different sizes and some catalyst residues.

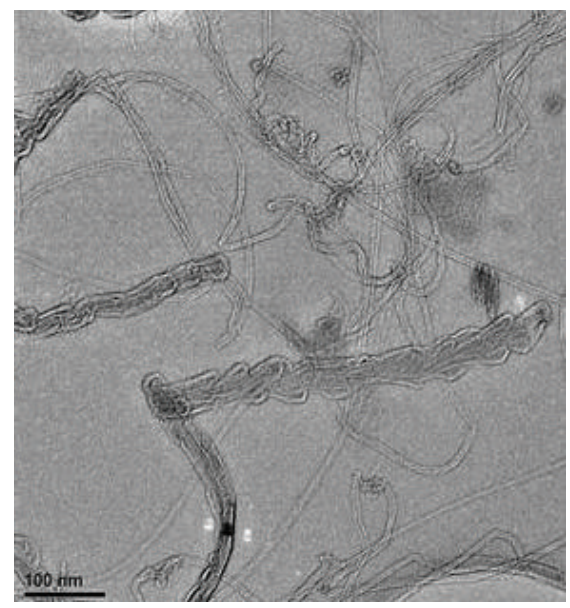

(a)

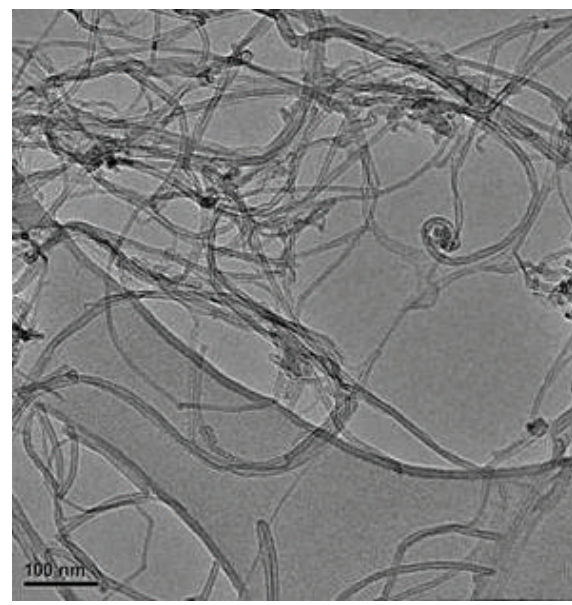

(b)

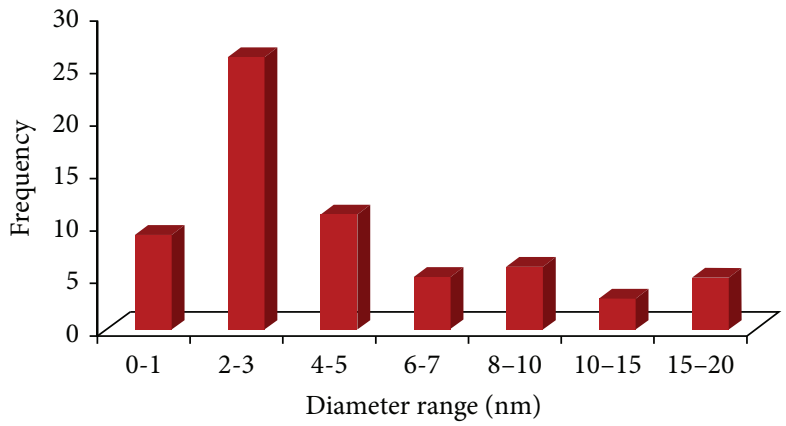

(c)

FIGURE 2: TEM micrographs of (a) pristine and (b) oxidised DWCNTs. The pristine DWCNTs have excess catalyst on their surfaces. The oxidised DWCNTs have clean surfaces with scattered dark spots which are catalyst residues. (c) A graph showing the diameter size distribution for the synthesized DWCNTs.

the concentration of smaller particles in the water column [28]. Similar results were reported for MWCNTs in aqueous suspensions where their aggregation increased when the $\mathrm{NaCl}$ concentration was doubled in the suspensions [29]. A general decrease in zeta potentials of both pristine and oxidised DWCNTs was observed with increased salinity (Figure 6). However, at $0.00835 \mathrm{M}$ IS, there was an increase in zeta potential for both oxidised and pristine DWCNTs.
This may be attributed to the low $\mathrm{Na}^{+}$concentration not having an effect on the electric double layer of DWCNTs. The subsequent decrease in zeta potential for both oxidised and pristine DWCNTs confirms the data obtained for hydrodynamic size that high aggregation resulted from the increase of $\mathrm{Na}^{+}$in suspensions. The positively charged metal ion, $\mathrm{Na}^{+}$, neutralises the surface charge on the surfaces of DWCNTs and compresses the double layer of the DWCNTs, 


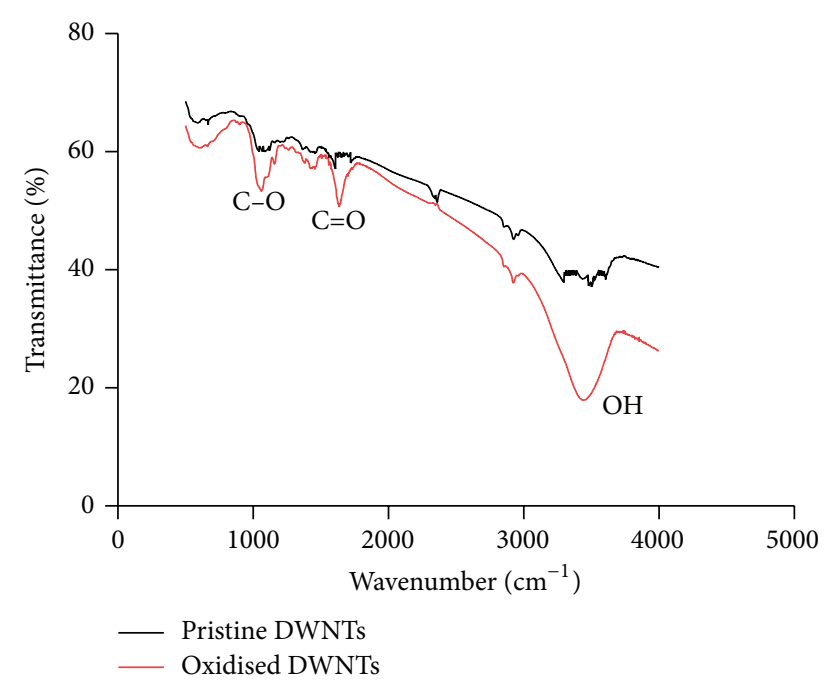

FIGURE 3: FT-IR of both pristine and oxidised DWCNTs illustrating the major functional groups present in oxidised DWCNTs which are not found in pristine DWCNTs.

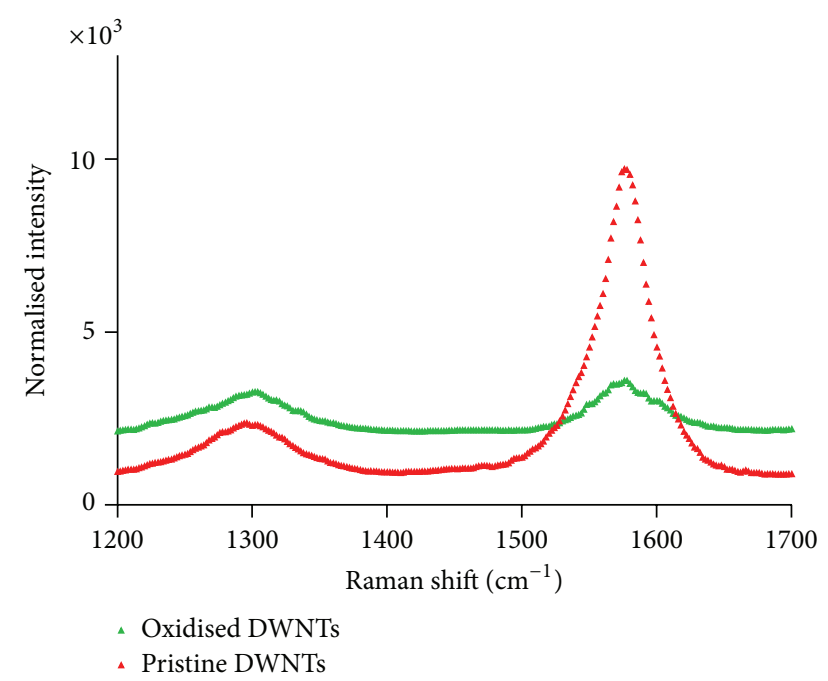

FIGURE 4: Raman spectra of pristine and oxidised DWCNTs showing different intensities of the D- and G-bands in both pristine and oxidised DWCNTs.

resulting in the reduction of electrostatic repulsion between DWCNTs [30]. $\mathrm{Na}^{+}$ions were reported to have an influence on the aggregation of MWCNTs at higher concentrations when compared to divalent cations such as $\mathrm{Mg}^{2+}$ and $\mathrm{Ca}^{2+}$. Such observations were attributed to the difference in the ionic strength resulting from the presence of monovalent and divalent cations in solution [29].

3.3.3. The Effect of $\mathrm{Ca}^{2+}$. Increased IS in water promotes aggregation in both pristine and oxidised DWCNTs as confirmed by the increased hydrodynamic particle size with increased hardness (Figure 7). Pristine DWCNTs had a larger hydrodynamic size at all water hardness levels.
It was found that zeta potential data correlated with the increased aggregation observed with increased IS. Pristine DWCNTs had a slightly lower average zeta potential at the different IS levels (Figure 7). There was a sharp decrease in zeta potential between $0 \mathrm{M}$ and $0.00449 \mathrm{M}$ for pristine DWCNTs followed by little change in zeta potential between IS of $0.00449 \mathrm{M}$ and $0.0226 \mathrm{M}$. DWCNTs in IS of $0.0339 \mathrm{M}$ showed a decrease in zeta potential.

Oxidised DWCNTs had a slight increase in zeta potential between IS of $0 \mathrm{M}$ and $0.00449 \mathrm{M}$. Thereafter a consistent decrease in zeta potential was observed with increased cation content (Figure 7).

Both DWCNT types had increased hydrodynamic sizes as the IS of water was increased. However, there was no noticeable increase in hydrodynamic size of both pristine and oxidised DWCNTs from the IS of 0.0226 to $0.0396 \mathrm{M}$. The zeta potential of oxidised DWCNTs increased slightly in IS of $0.00449 \mathrm{M}$ and decreased in the higher IS values (Figure 7). The zeta potential decrease at 0.00449 was not significantly different from the zeta potential of oxidised DWCNTs in distilled water. Pristine DWCNTs had decreased zeta potential with increased water hardness. However, the decrease was small (between $0.00449 \mathrm{M}$ and $0.0226 \mathrm{M}$ ). Divalent ions in water contribute towards the reduction of the double layer of particles resulting in the shielding of electrostatic charges of particles [31]. Divalent ions such as calcium have been reported to efficiently screen negative charges on CNT surfaces. The screening of the negative charges results in a shift of zeta potentials to less negative values [32]. The presence of calcium in MWCNT suspensions consequently increased their hydrodynamic size [32, 33]. In another study by Smith and coworkers, it was revealed that calcium cations have a greater influence on the aggregation of MWCNTs than sodium ions [29]. These observations were attributed to the higher ionic strength presented by $\mathrm{Ca}^{2+}$ in the suspensions at lower concentrations compared to that of $\mathrm{Na}^{+}$[29].

3.4. Effect of Humic Acid. There was a higher amount of smaller particles (DWCNT aggregates) suspended in water containing humic acid compared to the blanks. The zeta potentials of DWCNTs confirm that there was an increase in the repulsion energies of DWCNT particles.

Addition of humic acid to DWCNT suspensions resulted in more negative zeta potential values. It was shown that pristine DWCNTs had a consistent reduction in zeta potential up to around $2 \mathrm{mg} / \mathrm{L}$ of humic acid (Figure 8 ). The decrease in zeta potential was relatively small thereafter. This may be related to the maximum amount of humic acid that has an effect on the zeta potential of DWCNTs. There was a sharp decrease in zeta potential values of oxidised DWCNTs when the concentration of humic acid was between $0 \mathrm{mg} / \mathrm{L}$ and $1 \mathrm{mg} / \mathrm{L}$ humic acid. A slight increase in zeta potential between $1 \mathrm{mg} / \mathrm{L}$ and $3.64 \mathrm{mg} / \mathrm{L}$ was observed. Oxidised DWCNTs were found to have a higher increase in zeta potential when humic acid was added to oxidised DWCNT suspensions compared to pristine DWCNTs.

Humic substances are a fraction of natural organic matter and are ubiquitous in the aqueous environments. Humic 


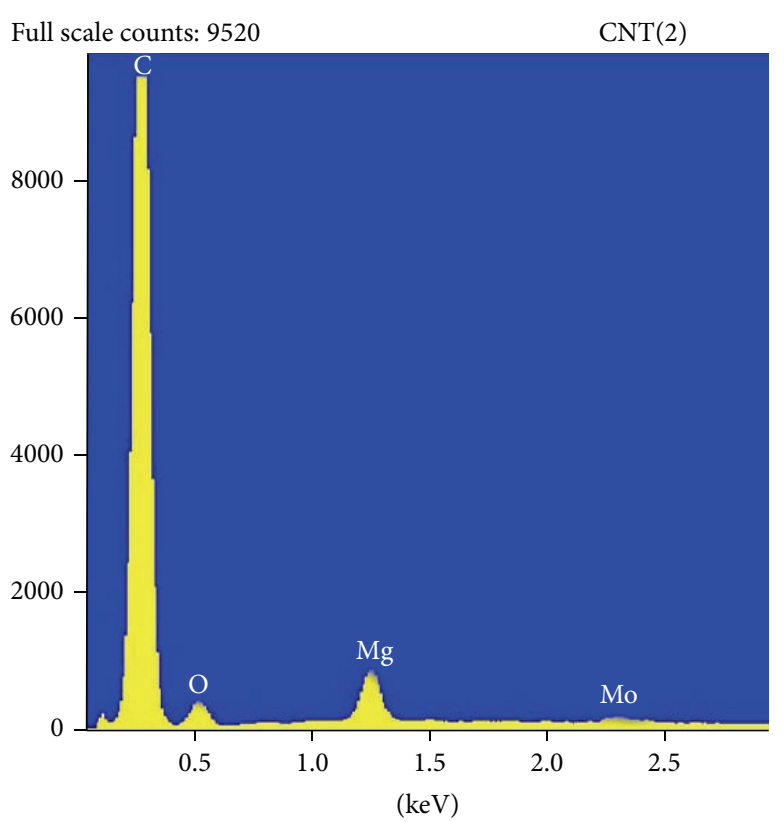

(a)

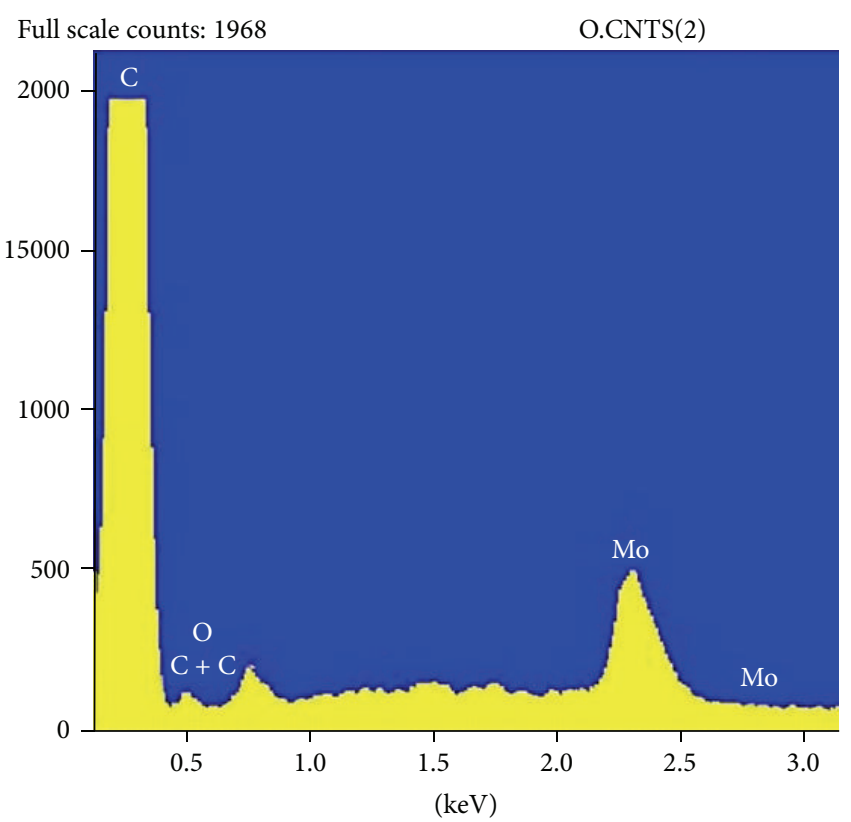

(b)

FIGURE 5: EDX spectra of (a) pristine and (b) oxidised DWCNTs showing their elemental composition.
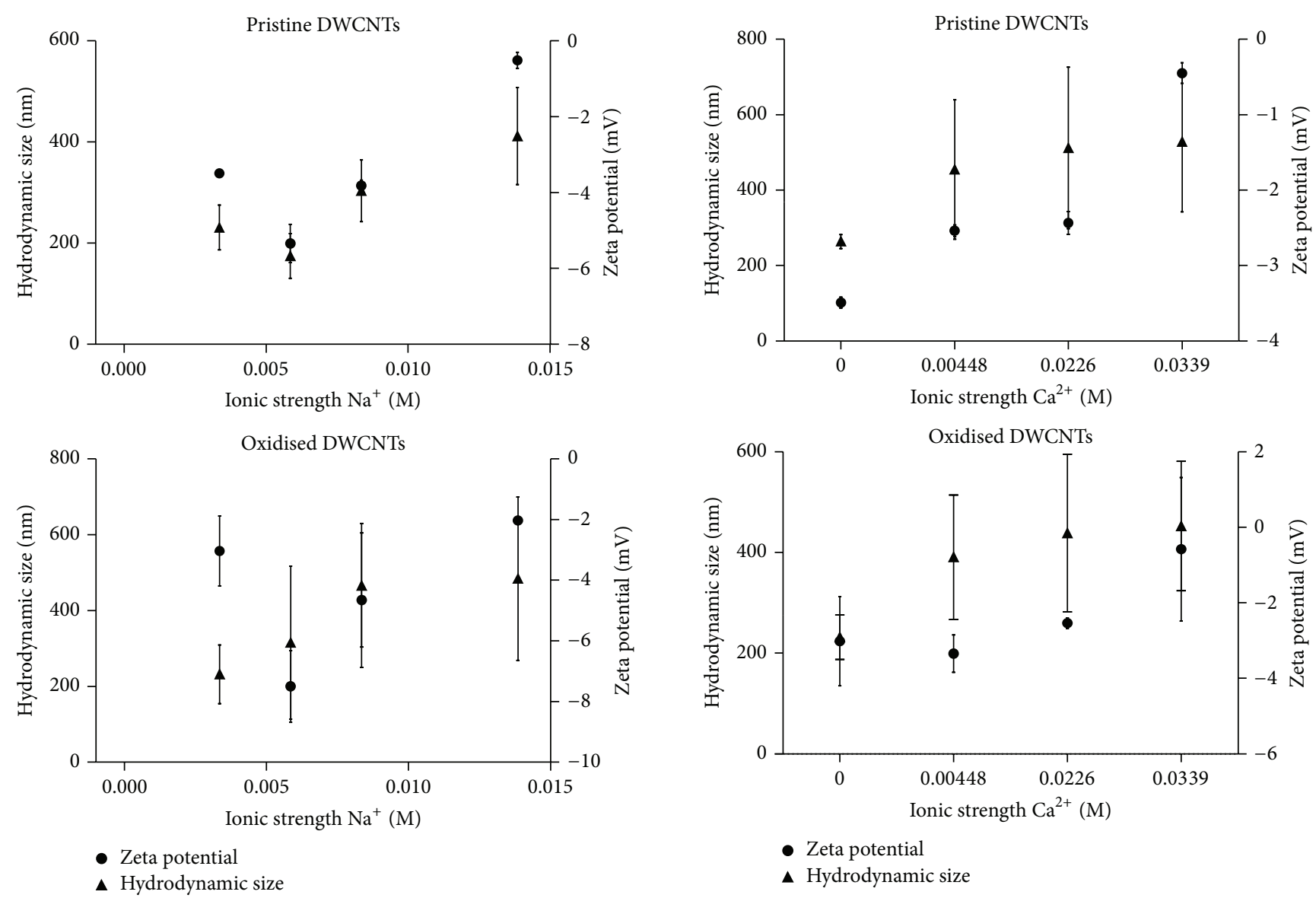

FIGURE 6: Hydrodynamic size and zeta potentials of DWCNTs at different IS $\left(\mathrm{Na}^{+}\right)$levels (error bars are the ranges of hydrodynamic FIgURE 7: Hydrodynamic size and zeta potentials of DWCNTs at different IS $\left(\mathrm{Ca}^{2+}\right)$ levels. 

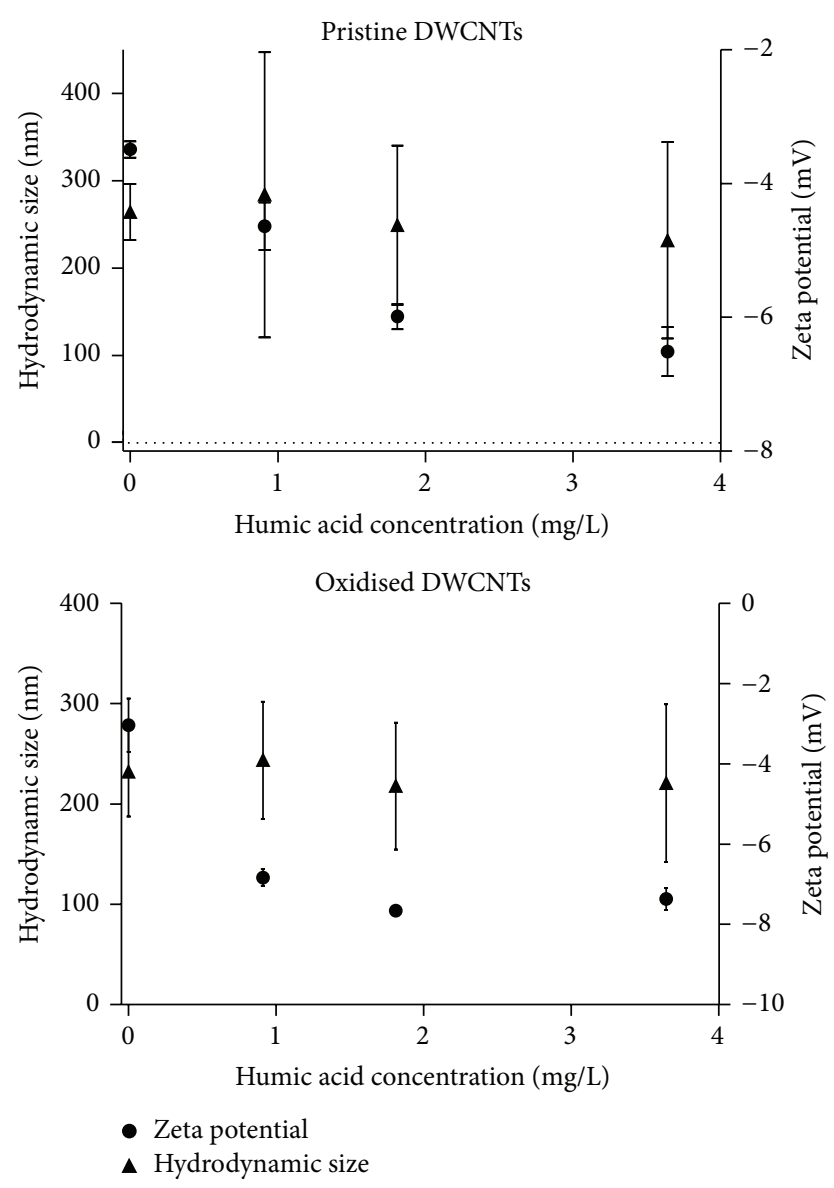

FIGURE 8: Hydrodynamic size and zeta potentials of DWCNTs at different humic acid levels.

acids are rich in aromatic moieties which, in theory, can interact with electron-rich surfaces such as graphene surfaces. Humic substances are known to decrease sedimentation rates of carbonaceous nanomaterials in aqueous suspensions [34]. The hydrodynamic size of particles in water containing humic acid decreased with an increase in humic acid concentration. Humic acid brings about a stabilising effect on MWNTs [32, $35,36]$. Pristine DWCNTs had a higher hydrodynamic particle size when compared to oxidised DWCNTs in humic acid. An increase in hydrodynamic particle size at approximately $1 \mathrm{mg} / \mathrm{L}$ of humic acid for pristine DWCNTs was observed. At higher humic acid concentrations, a consistent decrease in hydrodynamic particle size was noted. For oxidised DWCNTs, no change in hydrodynamic particle size at $1 \mathrm{mg} / \mathrm{L}$ humic acid was observed. In subsequent humic acid concentrations, however, a decrease in hydrodynamic particle size was observed. Corresponding zeta potentials were observed where more negative surface charges of DWCNTs were observed confirming that smaller hydrodynamic particle size is a result of steric stabilisation of DWCNTs in aqueous suspensions [37]. It should be noted that $\pi-\pi$ interactions are the main mechanism governing the sorption of humic acid on graphene surfaces of CNTs. The presence of electrondonating substituents on surfaces of MWCNTs enhances the sorption of polar moieties which are electron acceptors
[38, 39]. Moreover, oxygen containing functionalities on CNT surfaces have also been hypothesised to interact with humic acid through hydrogen bonding $[36,38]$. The latter, however, was identified as a less important driving force for the adsorption of humic acid to CNTs $[36,38]$. Schwyzer and colleagues reported that MWCNTs containing 4\% surface oxygen provided a better colloidal stability when suspended in Suwannee River humic acid (SRHA) than MWCNTs containing 2\% surface oxygen [32]. Schierz and Zänker also discovered that acid-functionalised MWNTs were more stable in water containing humic acid compared with pristine MWNTs [31]. Since humic acid is adsorbed on carbon nanotubes' surfaces, the sorbed humic acid inhibits aggregation through steric interactions imparted by the adsorbed humic macromolecules $[35,37,40]$. Surfactants such as sodium dodecyl sulphate (SDS) have previously been used to disperse DWCNTs in water. The average hydrodynamic size of the aggregates was $290 \mathrm{~nm}$, which was comparable to the average hydrodynamic size of oxidised DWCNTs in the current study [41].

3.5. Pseudokirchneriella subcapitata Growth Inhibition Test. The general trend in the exposure experiments done for this study is that there is an increase in growth inhibition with an increase in DWCNT concentration. Figure 4 illustrates the growth inhibition of algae by the different concentrations of agglomerated DWCNTs. It can be noted that the growth inhibition increases with increased DWCNT concentrations. For DWCNT concentrations between $0.708 \mathrm{mg} / \mathrm{L}$ and $25 \mathrm{mg} / \mathrm{L}$, there is no significant difference in the algae growth inhibition. A sharp increase can be observed for the highest concentration.

The growth inhibition caused by pristine DWCNTs was higher than that of oxidised DWCNTs. The $\mathrm{EC}_{50}$ of pristine DWCNTs was found to be $17.95 \mathrm{mg} / \mathrm{L}$ while oxidised DWCNTs had an $\mathrm{EC}_{50}$ of $10.93 \mathrm{mg} / \mathrm{L}$. Varied environmental parameters such as humic acid content and ionic strength (using both monovalent and divalent cations) resulted in the reduction of toxicity of both pristine and oxidised DWCNTs to P. subcapitata. The addition of humic acid $(3.64 \mathrm{mg} / \mathrm{L})$ to the exposure medium almost doubled the $\mathrm{EC}_{50} \mathrm{~s}$ of both types of DWCNTs. The $\mathrm{EC}_{50}$ of oxidised DWCNTs increased from $10.93 \mathrm{mg} / \mathrm{L}$ to $20.56 \mathrm{mg} / \mathrm{L}$ and the $\mathrm{EC}_{50}$ of pristine DWCNTs also increased from 17.95 to $31.65 \mathrm{mg} / \mathrm{L}$. The effects of ionic strength were determined by adding varying amounts of calcium carbonate and sodium chloride. It was found that decreased ionic strength $\left(\mathrm{Ca}^{2+}\right)$ resulted in lowered toxicity of DWCNTs. Also, increased ionic strength $\left(\mathrm{Ca}^{2+}\right)$ resulted in doubled $\mathrm{EC}_{50}$. Changing the ionic strength by adding lower amounts of $\mathrm{Na}^{+}$in exposure experiments resulted in significantly lowered toxicity of both pristine and oxidised DWCNTs. The ionic strength of $0.0139 \mathrm{M} \mathrm{Na}^{+}$ resulted in $\mathrm{EC}_{50} \mathrm{~S}$ above the highest exposure concentration $(50 \mathrm{mg} / \mathrm{L})$ for both pristine and oxidised DWCNTs. However, for oxidised DWCNTs the increased ionic strength resulting from added $\mathrm{Na}^{+}$did not result in a general decrease in the toxicity. In $0.00585 \mathrm{M} \mathrm{NaCl}$, the $\mathrm{EC}_{50}$ was $16.11 \mathrm{mg} / \mathrm{L}$ while in $0.00335 \mathrm{M}$, the $\mathrm{EC}_{50}$ was $26.22 \mathrm{mg} / \mathrm{L}$. It was found that 
only the highest $\mathrm{Na}^{+}$and $\mathrm{Ca}^{2+}$ concentrations resulted in significantly higher $\mathrm{EC}_{50} \mathrm{~s}$ than the other exposures (Table 1).

The algal cells were found to agglomerate with DWCNTs where a large amount of cells are entrapped in the DWCNT agglomerates. Figure 9 illustrates agglomeration of $P$. subcapitata with DWCNTs while some loose P. subcapitata cells surround the agglomerate.

Carbon nanotubes, SWCNT, DWCNTs, and MWCNT, have been reported to have an effect on the growth rates of various algal species [4, 42-45]. Such an effect has been found to be dose-dependent in all of these studies. Several researchers have reported that shading effect and agglomeration were the main causes of growth inhibition $[43,44]$. They further stated that each of these factors influenced growth to different extents [43]. The extent of aggregation of DWCNTs played a major role in the growth inhibition of $P$. subcapitata.

Humic acid reduced agglomeration of DWCNTs (Figure 8) and as a result, DWCNTs in the algal tests did not form large agglomerates that could trap algal cells and deprive them of illumination. At the highest humic acid concentration, growth inhibition resulting from exposure to both pristine and oxidised DWCNTs was lowered because at this humic acid concentration, DWCNTs formed smaller agglomerates reducing the amount of algae trapped in agglomerates. Schwab and coworkers [44] reported that NOM increased the toxicity of MWCNTs. It is worth noting that the NOM used in their study was about 20 times more than the concentration used in the current study. They concluded that the toxicity of CNTs is due to a hydrogen-bond based interaction between algal cells and NOM covered CNTs that causes the clogging of algae with CNTs [44]. However, such hydrogen bridges may have been very weak between humic acid and DWCNTs since the concentration of humic acid was much lower and hence the interaction could have been compromised.

Moreover, the amounts of shading presented by smaller agglomerates may have been lower than with larger agglomerates. This may be due to the fact that humic acid reduced the hydrodynamic size of DWCNT agglomerates in the exposure medium and increased the specific surface area for the interaction of algal cells with the DWCNTs. Shading effect has been reported to be the major contributor in the toxicity of CNTs to algae [44]. According to Long and colleagues, illumination is vital for cell propagation and the blockage from illumination by carbon nanotubes has a negative impact on the growth rates of algae [43]. However, Bennett and coworkers found that shading did not have a significant effect on the reduced growth rates observed in their study [44]. Such inconsistencies in engineered nanomaterials (ENMs) data are as a result of altered standard protocols. For algal toxicity tests, the major sources of error are the methods employed to quantify growth [10]. Due to their particulate matter and dark colour, CNTs interfere with signal detection in spectrophotometric methods commonly employed to quantify algal growth. Consequently, manual cell counting used in this study has been identified as a reliable method for monitoring algal growth $[10,43,44]$.

To vary the ionic strength, divalent and monovalent cations, respectively, were added to the exposure bioassays.

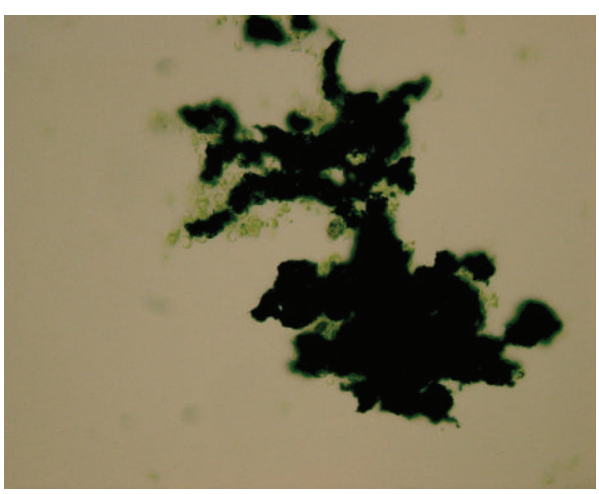

FIgURE 9: A light microscope picture of agglomeration of P. sub-capitata with DWCNTs (some loose cells can be seen around agglomerate).

These cations influence the rate of agglomeration of nanoparticles such as DWCNTs since $\mathrm{Ca}^{2+}$ and $\mathrm{Na}^{+}$cause rapid agglomeration of CNTs. From Figures 6 and 7, it can be seen that these cations reduced the zeta potential of both pristine and oxidised DWCNTs and resulted in the formation of large agglomerates. We propose that, during the exposure experiment, the algae addition stage is likely to have taken place after DWCNTs had formed agglomerates and had settled at the bottom of the flask. These agglomerates had not trapped algal cells as they settled and had limited impact on the growth inhibition. However, this scenario does not eliminate the interaction between algae and the agglomerates.

Double-walled carbon nanotubes have been reported to have different toxicities to a marine algal species, Thalassiosira pseudonana, depending on the method of mixing. Sonicated DWCNTs had an $\mathrm{EC}_{50}$ of $1.86 \mathrm{mg} / \mathrm{L}$ while stirred DWCNTs had an $\mathrm{EC}_{50}$ of $22.7 \mathrm{mg} / \mathrm{L}$ [4]. The $\mathrm{EC}_{50}$ of MWCNTs to another marine algae species, Dunaliella tertiolecta, was $0.82 \pm$ $0.02 \mathrm{mg} / \mathrm{L}$. In this study, however, the method of mixing was not specified [46]. The $\mathrm{EC}_{50}$ is comparable to the $\mathrm{EC}_{50}$ of sonicated DWCNTs in the former mentioned study. A fixed concentration, $0.5 \mathrm{mg} / \mathrm{L}$, of single-walled carbon nanotubes dispersed in $0.023 \%$ gum Arabic resulted in ca. $60 \%$ reduction in growth rates of $P$. subcapitata [42].

The acute toxicity of CNTs reported in the literature varies by orders of magnitude, especially for MWCNTs. The main reason for such variation is a result of differences in methods used to conduct toxicity tests and methods of evaluating cell densities in the algal toxicity test [10].

Oxidised DWCNTs were generally more toxic than pristine DWCNTs in all experiments. Wei and coauthors suggest that the toxicity is mediated through initial interaction between algal cells and CNTs [46]. With oxidised DWCNTs, there is a high probability that the interactions between the DWCNTs and algae cells were increased since oxidised DWCNTs had lower agglomeration compared to pristine DWCNTs. Wei and colleagues further observed that the interaction between algal cells and CNTs was stronger than steric and electrostatic repulsions between the negatively charged CNTs and algae [46]. The increased interaction between oxidised CNTs has been attributed to the formation 
TABLE 1: Growth inhibition (EC $\mathrm{E}_{50} \mathrm{~s}$ and $95 \%$ confidence intervals) for Pseudokirchneriella subcapitata following $72 \mathrm{~h}$ exposure to pristine and oxidised DWCNTs at different ionic strengths and humic acid (HA) concentrations. $\mathrm{EC}_{50} \mathrm{~s}$ with common alphabetical superscript do not differ significantly $(P<0.05)$.

\begin{tabular}{|c|c|c|c|}
\hline Exposure & Physicochemical characteristics & $\mathrm{EC}_{50}(\mathrm{mg} / \mathrm{L})$ & Confidence limits (mg/L) \\
\hline \multirow{4}{*}{ Pristine } & 0.00335 (control reconstituted water) $\mathrm{M} \mathrm{Na}$ & $17.95^{\mathrm{a}}$ & $9.8-26.72$ \\
\hline & $0.00585 \mathrm{M} \mathrm{Na}$ & $29.47^{\mathrm{a}}$ & $22.95-37.65$ \\
\hline & $0.00835 \mathrm{M} \mathrm{Na}$ & $30.89^{\mathrm{a}}$ & $18.06-40.4$ \\
\hline & $0.0139 \mathrm{M} \mathrm{Na}$ & $52.31^{\mathrm{b}}$ & $33.96-76.1$ \\
\hline \multirow{4}{*}{ Oxidised } & 0.00335 (control reconstituted water) $\mathrm{M} \mathrm{Na}$ & $10.93^{\mathrm{a}}$ & $6.71-15.59$ \\
\hline & $0.00585 \mathrm{M} \mathrm{Na}$ & $27.22^{\mathrm{a}}$ & $19.56-38.9$ \\
\hline & $0.00835 \mathrm{M} \mathrm{Na}$ & $16.11^{\mathrm{a}}$ & $11.59-22.42$ \\
\hline & $0.0139 \mathrm{M} \mathrm{Na}$ & $49.31^{\mathrm{b}}$ & $27.24-58.89$ \\
\hline \multirow{3}{*}{ Pristine } & $0.00449 \mathrm{M} \mathrm{Ca}$ & $23.26^{\mathrm{a}}$ & $17.04-28.00$ \\
\hline & $0.0226 \mathrm{M} \mathrm{Ca}$ & $25.57^{\mathrm{a}}$ & $16.07-34.93$ \\
\hline & $0.0339 \mathrm{M} \mathrm{Ca}$ & $31.52^{\mathrm{a}}$ & $21.56-50.92$ \\
\hline \multirow{3}{*}{ Oxidised } & $0.00449 \mathrm{M} \mathrm{Ca}$ & $22.86^{\mathrm{a}}$ & $15.59-42.42$ \\
\hline & $0.0226 \mathrm{M} \mathrm{Ca}$ & $22.91^{\mathrm{a}}$ & $12.95-40.89$ \\
\hline & $0.03395 \mathrm{M} \mathrm{Ca}$ & $24.61^{\mathrm{a}}$ & $13.37-34.44$ \\
\hline \multirow{4}{*}{ Pristine } & 0 (control reconstituted water) $\mathrm{M} \mathrm{Na}$ & $17.95^{\mathrm{b}}$ & $9.80-26.72$ \\
\hline & $0.9 \mathrm{mg} / \mathrm{L} \mathrm{HA}$ & $22.75^{\mathrm{a}}$ & $14.39-31.70$ \\
\hline & $1.81 \mathrm{mg} / \mathrm{L} \mathrm{HA}$ & $26.56^{\mathrm{a}}$ & $10.95-34.61$ \\
\hline & $3.64 \mathrm{mg} / \mathrm{L} \mathrm{HA}$ & $31.65^{\mathrm{a}}$ & $10.87-42.19$ \\
\hline \multirow{4}{*}{ Oxidised } & 0 (control reconstituted water) $\mathrm{M} \mathrm{Na}$ & $10.93^{\mathrm{a}}$ & $6.71-15.59$ \\
\hline & $0.9 \mathrm{mg} / \mathrm{L} \mathrm{HA}$ & $13.59^{\mathrm{a}}$ & $8.71-21.19$ \\
\hline & $1.81 \mathrm{mg} / \mathrm{L} \mathrm{HA}$ & $18.01^{\mathrm{a}}$ & $16.71-24.93$ \\
\hline & $3.64 \mathrm{mg} / \mathrm{L} \mathrm{HA}$ & $20.56^{\mathrm{a}}$ & $6.58-34.15$ \\
\hline
\end{tabular}

of hydrogen bonds between cell surfaces and oxygen defects [44]. This hydrogen bond formation was also the reason why interactions between DWCNTs with humic acid and algal cells increased and consequently increased the toxicity of these DWCNTs.

3.6. Daphnia pulex Immobilisation/Lethality Test. The acute toxicities of both pristine and oxidised DWCNTs to D. pulex were determined and the $\mathrm{LC}_{50} \mathrm{~s}$ were found to be in different orders of magnitude with $D$. pulex being the most sensitive in all experimental conditions studied. The mean $\mathrm{EC}_{50} \mathrm{~s}$ of D. pulex ranged between $1.801 \mathrm{mg} / \mathrm{L}$ and $4.480 \mathrm{mg} / \mathrm{L}$ (for both pristine and oxidised DWCNTs). Table 2 illustrates the average $\mathrm{EC}_{50}$ s of DWCNT under the experimental conditions studied.

Oxidised DWCNTs were generally less toxic to D. pulex than pristine DWCNTs. The $\mathrm{EC}_{50}$ of oxidised DWCNTs was $3.565 \mathrm{mg} / \mathrm{L}$ and addition of both humic acid and ionic strength $\left(\mathrm{Ca}^{2+}\right.$ and $\left.\mathrm{Na}^{+}\right)$increased the toxicity of both pristine and oxidised DWCNTs. Addition of humic acid reduced the $\mathrm{EC}_{50}$ of pristine DWCNTs to below $2 \mathrm{mg} / \mathrm{L}$ while $\mathrm{Na}^{+}$reduced the $\mathrm{EC}_{50}$ to about $2.5 \mathrm{mg} / \mathrm{L}$. Pristine DWCNTs in daphnia medium had an $\mathrm{EC}_{50}$ of $4.48 \mathrm{mg} / \mathrm{L}$ and the addition of humic acid and $\mathrm{Ca}^{2+}$ and $\mathrm{Na}^{+}$reduced the $\mathrm{EC}_{50}$ to about $3 \mathrm{mg} / \mathrm{L}$ for all experimental conditions.

The exposed organisms were studied under a light microscope to visualise how the organisms interact with the
DWCNTs. Daphnia pulex were found to have large amounts of dark material in their gut tract after exposure to DWCNTs. Ingestion was the main mode of uptake of DWCNTs by $D$. pulex. Figure 10 displays D. pulex after exposure to DWCNTs and the amount of DWCNTs in the gut tract of D. pulex was found to be dependent on the DWCNT concentration in exposure solutions. A similar trend was observed for both pristine and oxidised DWCNTs. Similar findings were reported for D. magna exposed to several nanoparticles such as SWCNTs, $\mathrm{C}_{60}$, MWCNT, and titanium dioxide [47].

Visual inspection of $D$. pulex at 40x magnification under a light microscope suggested that the acute toxicity of DWCNTs was a physical effect attributed to clogging of the daphnid gut tract. Such clogging is likely to interfere with food processing in Daphnia pulex [48].

Pristine DWCNTs were found to be more toxic to $D$. pulex than oxidised DWCNTs. Pristine DWCNTs have a greater penchant to aggregate leading to the formation of more structurally complex aggregate arrays that interact differently within the gut of $D$. pulex. Nonfunctionalised MWNTs were reported to be more toxic than functionalised MWNTs to Ceriodaphnia dubia [48]. Depuration experiments also revealed that C. dubia had difficulty clearing the nanoparticles from the gut tracts even after $48 \mathrm{~h}$. The interactions have been proposed by Kennedy et al. to be either physical or chemical [48]. Humic acid generally increased the toxicity of both types of DWCNTs. Since humic acid reduces 
TABLE 2: Lethal concentrations ( $\mathrm{LC}_{50} \mathrm{~s}$ and $95 \%$ confidence intervals) for Daphnia pulex following $48 \mathrm{~h}$ exposure to pristine and oxidised DWCNTs at different ionic strengths and humic acid (HA) concentrations. $\mathrm{LC}_{50} \mathrm{~s}$ with common alphabetical superscript do not differ significantly $(P<0.05)$.

\begin{tabular}{|c|c|c|c|c|}
\hline Exposure & \multicolumn{2}{|c|}{ Physicochemical characteristics } & $\mathrm{EC}_{50}(\mathrm{mg} / \mathrm{L})$ & Confidence limits $(\mathrm{mg} / \mathrm{L})$ \\
\hline \multirow{4}{*}{ Pristine } & \multicolumn{2}{|c|}{0.00335 (control reconstituted water) $\mathrm{M} \mathrm{Na}$} & $2.801^{\mathrm{a}}$ & $1.58-3.95$ \\
\hline & \multicolumn{2}{|c|}{$0.00585 \mathrm{M} \mathrm{Na}$} & $2.710^{\mathrm{a}}$ & $1.21-7.58$ \\
\hline & \multicolumn{2}{|c|}{$0.00835 \mathrm{M} \mathrm{Na}$} & $2.835^{\mathrm{a}}$ & $0.82-5.66$ \\
\hline & \multicolumn{2}{|c|}{$0.0139 \mathrm{M} \mathrm{Na}$} & $3.163^{\mathrm{a}}$ & $2.10-6.02$ \\
\hline \multirow{4}{*}{ Oxidised } & \multicolumn{2}{|c|}{0.00335 (control reconstituted water) $\mathrm{M} \mathrm{Na}$} & $4.480^{\mathrm{a}}$ & $2.09-7.49$ \\
\hline & \multicolumn{2}{|c|}{$0.00585 \mathrm{M} \mathrm{Na}$} & $3.320^{\mathrm{a}}$ & $1.88-6.04$ \\
\hline & \multicolumn{2}{|c|}{$0.00835 \mathrm{M} \mathrm{Na}$} & $3.048^{\mathrm{a}}$ & $1.71-7.05$ \\
\hline & \multicolumn{2}{|c|}{$0.0139 \mathrm{M} \mathrm{Na}$} & $3.541^{\mathrm{a}}$ & $1.52-6.35$ \\
\hline \multirow{3}{*}{ Pristine } & \multicolumn{2}{|c|}{$0.00449 \mathrm{M} \mathrm{Ca}$} & \multirow{2}{*}{$\begin{array}{c}3.048^{\mathrm{a}} \\
281^{\mathrm{a}}\end{array}$} & $1.51-6.43$ \\
\hline & \multicolumn{2}{|c|}{$0.0226 \mathrm{M} \mathrm{Ca}$} & & $1.58-3.95$ \\
\hline & \multicolumn{2}{|c|}{$0.03395 \mathrm{M} \mathrm{Ca}$} & $3.327^{\mathrm{a}}$ & $1.72-6.44$ \\
\hline \multirow{3}{*}{ Oxidised } & \multicolumn{2}{|c|}{$0.00449 \mathrm{M} \mathrm{Ca}$} & $3.77^{\mathrm{a}}$ & $1.01-5.49$ \\
\hline & \multicolumn{2}{|c|}{$0.0226 \mathrm{M} \mathrm{Ca}$} & $4.48^{\mathrm{a}}$ & $2.09-7.49$ \\
\hline & \multicolumn{2}{|c|}{$0.03395 \mathrm{M} \mathrm{Ca}$} & $3.57^{\mathrm{a}}$ & $1.81-7.58$ \\
\hline \multirow{4}{*}{ Pristine } & \multicolumn{2}{|c|}{0 (control reconstituted water) $\mathrm{M} \mathrm{Na}$} & $2.80^{\mathrm{a}}$ & $1.58-3.95$ \\
\hline & 0.9 & g/L HA & $1.91^{\mathrm{a}}$ & $1.21-7.58$ \\
\hline & 1.81 & hg/L HA & $1.89^{\mathrm{a}}$ & $0.82-5.66$ \\
\hline & 3.64 & $\mathrm{ng} / \mathrm{L} \mathrm{HA}$ & $1.80^{\mathrm{a}}$ & $1.10-6.02$ \\
\hline & 0 (control recor & tituted water) $\mathrm{M} \mathrm{Na}$ & $4.48^{\mathrm{a}}$ & $2.09-7.49$ \\
\hline Oxidised & 0.9 & $\mathrm{~g} / \mathrm{L}$ HA & $4.07^{\mathrm{a}}$ & $1.88-6.75$ \\
\hline DAluised & 1.81 & ig/L HA & $3.25^{\mathrm{a}}$ & $1.71-7.05$ \\
\hline & 3.64 & $\mathrm{ng} / \mathrm{L}$ HA & $3.07^{\mathrm{a}}$ & $1.52-6.87$ \\
\hline & Unexposed D. pulex & $\begin{array}{l}\text { D. pulex exposed to } 0.625 \mathrm{mgh} \\
\text { DWCNTs }\end{array}$ & $\begin{array}{l}\text { D. oulex exposed to } 1.25 \mathrm{mg} / \mathrm{L} \\
\text { DWCNTs }\end{array}$ & $\begin{array}{l}\text { D. pulex exposed to } 2.5 \mathrm{mgh} \\
\text { DWCNTs }\end{array}$ \\
\hline
\end{tabular}

FIGURE 10: Changes in the density of oxidised DWCNTs in the gut tract of D. pulex with increasing exposure concentrations.

aggregation in DWCNTs, the average hydrodynamic size of DWCNTs is reduced. With reduced hydrodynamic size, the concentration of DWCNTs in aqueous solution increases and the potential biological effect is increased. In a study carried out by Edgington and coworkers it was reported that increasing DOC concentration (Suwannee River-NOM) did not have an effect on the toxicity [49]. They speculated that the MWCNTs were saturated with the SR-NOM at very low DOC concentration and had no effect on stabilisation of MWCNTs in exposure medium. There was no observable pattern in the results obtained; hence they concluded that increasing DOC concentration had no impact on the toxicity of MWCNTs. This was not the case in the current study as the average $\mathrm{LC}_{50} \mathrm{~S}$ did show an increase in toxicity with increased DOC concentrations (Table 2). The observed increase for both pristine and oxidised DWCNTs was, however, statistically not significant $(P<0.05)$. These results suggest that reduced aggregation resulting from the addition of humic acid (Figure 8) increased probabilities of DWCNT uptake by $D$. pulex.

The increase in ionic strength decreased the toxicity of both pristine and oxidised DWCNTs. Increase of $\mathrm{Na}^{+}$ did not have an effect on the toxicity of pristine DWCNTs but reduced the average $\mathrm{LC}_{50}$ of oxidised DWCNTs. Data on hydrodynamic size results show that increased ionic strength increased the hydrodynamic size of both pristine and oxidised DWCNTs with increased $\mathrm{Ca}^{2+}$ having a greater effect than increased $\mathrm{Na}^{+}$. The concentration of DWCNTs in these suspensions per unit volume is decreased and thus the amount of DWCNTs ingested by daphnia in such exposure conditions is low and results in lower biological effect. It is 
TABLE 3: Lethal concentrations ( $\mathrm{LC}_{50} \mathrm{~s}$ and $95 \%$ confidence intervals) for Poecilia reticulata following $96 \mathrm{~h}$ exposure to pristine and oxidised double-walled carbon nanotubes at different ionic strengths and humic acid (HA) concentrations. LC $_{50} \mathrm{~s}$ with common alphabetical superscript do not differ significantly $(P<0.05)$.

\begin{tabular}{|c|c|c|c|}
\hline Exposure & Physicochemical characteristics & $\mathrm{EC}_{50}(\mathrm{mg} / \mathrm{L})$ & Confidence limits (mg/L) \\
\hline \multirow{4}{*}{ Pristine } & 0.00335 (control reconstituted water) $\mathrm{M} \mathrm{Na}$ & $113.64^{\mathrm{a}}$ & $43.34-267.66$ \\
\hline & $0.00585 \mathrm{M} \mathrm{Na}$ & 261.0 & $110.7-447.20$ \\
\hline & $0.00835 \mathrm{M} \mathrm{Na}$ & $>500$ & \\
\hline & $0.0139 \mathrm{M} \mathrm{Na}$ & $>500$ & \\
\hline \multirow{4}{*}{ Oxidised } & 0.00335 (control reconstituted water) $\mathrm{M} \mathrm{Na}$ & $214^{\mathrm{a}}$ & $89.9-269$ \\
\hline & $0.0083585 \mathrm{M} \mathrm{Na}$ & $>500$ & \\
\hline & $0.00835 \mathrm{M} \mathrm{Na}$ & $>500$ & \\
\hline & $0.0139 \mathrm{M} \mathrm{Na}$ & $>500$ & \\
\hline \multirow{3}{*}{ Pristine } & $0.00449 \mathrm{M} \mathrm{Ca}$ & $112.53^{\mathrm{a}}$ & $50.60-316.60$ \\
\hline & $0.0226 \mathrm{M} \mathrm{Ca}$ & $113.64^{\mathrm{a}}$ & $43.66-113.64$ \\
\hline & $0.03395 \mathrm{M} \mathrm{Ca}$ & $>500$ & \\
\hline \multirow{3}{*}{ Oxidised } & $0.00449 \mathrm{M} \mathrm{Ca}$ & $274.17^{\mathrm{a}}$ & $113-439$ \\
\hline & $0.0226 \mathrm{M} \mathrm{Ca}$ & $214^{\mathrm{a}}$ & $89.9-269.1$ \\
\hline & $0.03395 \mathrm{M} \mathrm{Ca}$ & $>500$ & \\
\hline \multirow{4}{*}{ Pristine } & 0 (control reconstituted water) $\mathrm{M} \mathrm{Na}$ & $113.64^{\mathrm{a}}$ & $43.34-267.66$ \\
\hline & $0.9 \mathrm{mg} / \mathrm{L} \mathrm{HA}$ & $106.93^{\mathrm{a}}$ & $66.88-139.03$ \\
\hline & $1.81 \mathrm{mg} / \mathrm{L} \mathrm{HA}$ & $84.15^{\mathrm{a}}$ & $28.00-171.27$ \\
\hline & $3.64 \mathrm{mg} / \mathrm{L} \mathrm{HA}$ & $64.56^{\mathrm{a}}$ & $19.23-122.02$ \\
\hline \multirow{4}{*}{ Oxidised } & 0 (control reconstituted water) $\mathrm{M} \mathrm{Na}$ & $214.00^{\mathrm{a}}$ & $89.90-269.1$ \\
\hline & $0.9 \mathrm{mg} / \mathrm{L} \mathrm{HA}$ & $193.77^{\mathrm{b}}$ & $97.44-287.11$ \\
\hline & $1.81 \mathrm{mg} / \mathrm{L} \mathrm{HA}$ & $195.33^{\mathrm{b}}$ & $91.7-322.30$ \\
\hline & $3.64 \mathrm{mg} / \mathrm{L} \mathrm{HA}$ & $184.0^{\mathrm{b}}$ & $100.3-316.10$ \\
\hline
\end{tabular}

possible that the DWCNT concentration per unit volume did not decrease when $\mathrm{Na}^{+}$was increased as it did in the case of $\mathrm{Ca}^{2+}$.

Daphnia species are filter feeders and can take up large volumes of water when compared to body size [50]. They can ingest particles in the size range of $0.4 \mu \mathrm{m}$ to $40 \mu \mathrm{m}$. This range includes algae and inorganic and organic particles [50, 51]. The single DWCNTs and their aggregates are within the lower end of the size range that can be ingested by Daphnia species.

In a study carried out on D. magna by Zhu and coworkers, they reported that the $\mathrm{LC}_{50}$ of nonfunctionalised SWCNTs was $2.425 \mathrm{mg} / \mathrm{L}$ while unfunctionalised MWCNTs had an $\mathrm{LC}_{50}$ of $22.751 \mathrm{mg} / \mathrm{L}$ [47]. The $\mathrm{LC}_{50}$ of DWCNTs $(2.81 \mathrm{mg} / \mathrm{L})$ falls in between these values but is within the same order of magnitude of SWCNTs. Such findings suggest that the size of carbon nanotubes plays a role in the mediation of toxicity in Daphnia species. Theory suggests that smaller particles are likely to be more toxic as a result of their larger specific surface area which is conducive to greater nanoparticle-cell interaction.

Moreover, the presence of DWCNTs in the gut tract of $D$. pulex suggests that the gut is the main organ that interacts with DWCNTs. Zhu and coauthors suggested that the gut is where cell death occurs and consequently results in organism mortality [47].
3.7. Poecilia reticulata Lethality Test. Pristine DWCNTs were found to be more toxic to $P$. reticulata than oxidised DWCNTs. The average $\mathrm{LC}_{50}$ of pristine DWCNTs was $113.64 \mathrm{mg} / \mathrm{L}$ while oxidised DWCNTs had an $\mathrm{LC}_{50}$ of $214 \mathrm{mg} / \mathrm{L}$. In the bioassays assessing the effect of humic acid and ionic strength, pristine DWCNTs were more toxic than oxidised DWCNTs in all conditions. In varied ionic strength $\left(\mathrm{Na}^{+}\right)$, both pristine and oxidised DWCNTs had lowered toxicity as the salinity increased. At an ionic strength of $0.00585 \mathrm{M}$ and $0.0139 \mathrm{M} \mathrm{Na}^{+}$, the $\mathrm{LC}_{50}$ of both pristine and oxidised DWCNTs had lethal concentrations higher than the concentration of the stock suspensions $(500 \mathrm{mg} / \mathrm{L})$. In ionic strengths of $0 \mathrm{M} \mathrm{Ca}^{2+}$ and $0.00449 \mathrm{M} \mathrm{Ca}^{2+}$, reduced toxicity for both pristine and oxidised DWCNT was observed. At an ionic strength of $0.0226 \mathrm{M}$, the highest ionic strength $\left(\mathrm{Ca}^{2+}\right)$, the toxicity was lowered such that the $\mathrm{LC}_{50}$ in hard water was higher than the concentration of the stock suspensions $(500 \mathrm{mg} / \mathrm{L})$.

In experiments on the effect of humic acid, the toxicity of DWCNTs was increased as the concentration of humic acid increased. For pristine DWCNTs, the $\mathrm{LC}_{50}$ at $0 \mathrm{mg} / \mathrm{L}$ humic acid was $113.64 \mathrm{mg} / \mathrm{L}$ and at the highest humic acid concentration, it was $3.64 \mathrm{mg} / \mathrm{L}$ (Table 3).

Fish have been reported to ingest CNTs through the gastric tract. The amount of ingested CNTs depends on the colloidal stability of ENMs in solution [21]. The high agglomeration of DWCNTs at high ionic strengths (Figures 2 


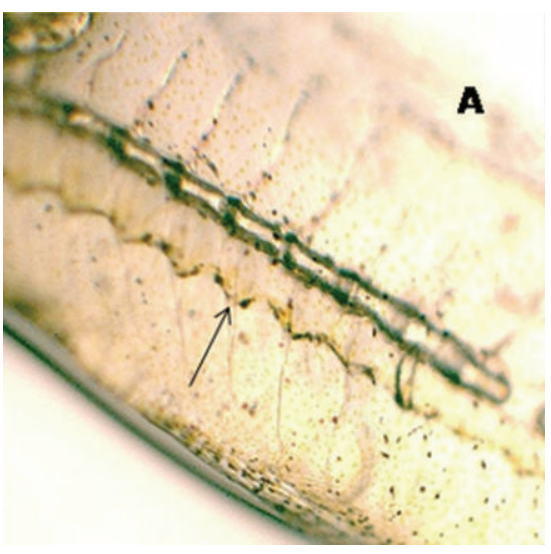

(a)

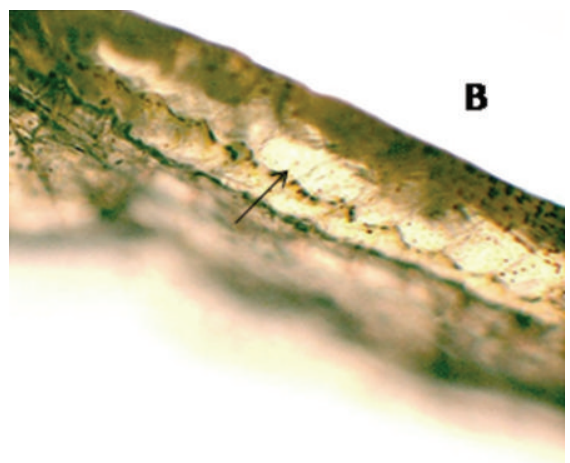

(b)

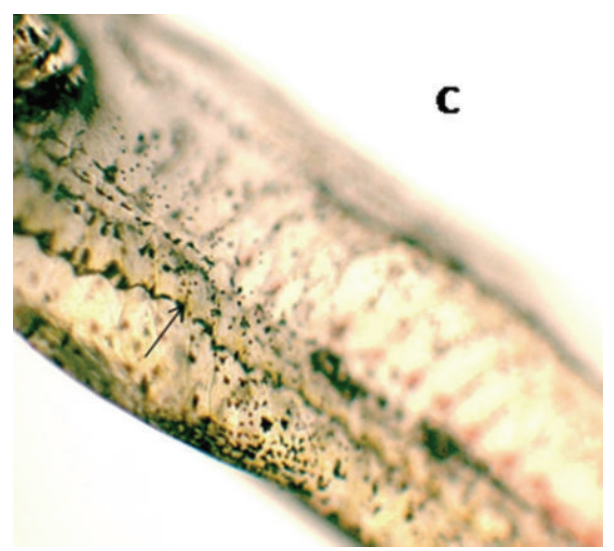

(c)

FIgURE 11: Pictures illustrating the gut of fish exposed to fish medium only (a), to $62.5 \mathrm{mg} / \mathrm{L}$ DWCNTs (b), and to $250 \mathrm{mg} / \mathrm{L}$ DWCNTs (c).

and 3 ) removed some of the test material through the settling of DWCNTs at the bottom of the exposure vessels. However, when humic acid was added to exposure experiments, it stabilised some of the DWCNTs in solution and this has been reported to increase the concentration of DWCNTs per unit volume in the water column, increasing the probability of the ingestion of DWCNTs by the fish [52]. This may be the reason for the slight increase in toxicity of the DWCNTS when there are some stabilised CNTs in solution. Figure 11 shows the digestive tract of $P$. reticulata that were exposed to DWCNT suspensions. It can be noted that the amount of DWCNTs increases when the exposure concentration increases.

Freshwater fish such as $P$. reticulata has water intak proportional to their body mass at a given time [53]. Studies on medaka and rainbow trout demonstrated the presence of nanoparticles, including CNTs, in the gut of fish [54, 55]. Such data suggest that while drinking water, freshwater fish ingest nanoparticles. The internalised nanoparticles lead to stress-induced drinking, consequently leading to an increased amount of internalised nanoparticles [53]. This uptake mechanism is dependent on the aggregation state of DWCNTs $[10,53,55]$. The agglomeration of DWCNTs removed some of the test material through the settling of DWCNTs at the bottom of the exposure vessels. The addition of humic acid in exposure experiments stabilised some of the DWCNTs in solution and this has been reported to increase the amount of carbon nanoparticles internalised by the fish $[42,55]$. The acute toxicity of both pristine and oxidised DWCNTs in increased humic acid content increased because $P$. reticulata ingested more DWCNTs and DWCNT aggregates with lower hydrodynamic sizes.

The stabilisation of DWCNTs in the water column by humic acid increases the probability of contact between fish and nanoparticles through diet, hence the slight increase in toxicity [55]. Capping agents such as natural organic matter, tannic acid, Tween 20, and gum Arabic (GA) have been reported to have an effect on the toxicity of ENMs such as MWCNTs [35, 56-58]. These dispersants or capping agents alter the ENM-cell contact opportunities and consequently alter the toxicity of such materials [55]. In the gut, DWCNTs are likely to be trapped in the mucus layer of the gut, increasing the likelihood that the DWCNTs will interact with the apical surface of the epithelium, hence the slight increase in toxicity. Gill mucus of rainbow trout trapped SWCNTs and increased gill pathology [54]. In this scenario, the surface charge, whether anionic or cationic, does not determine the interaction of the nanoparticles and cells. The nonspherical shape of DWCNTs enables them to get 

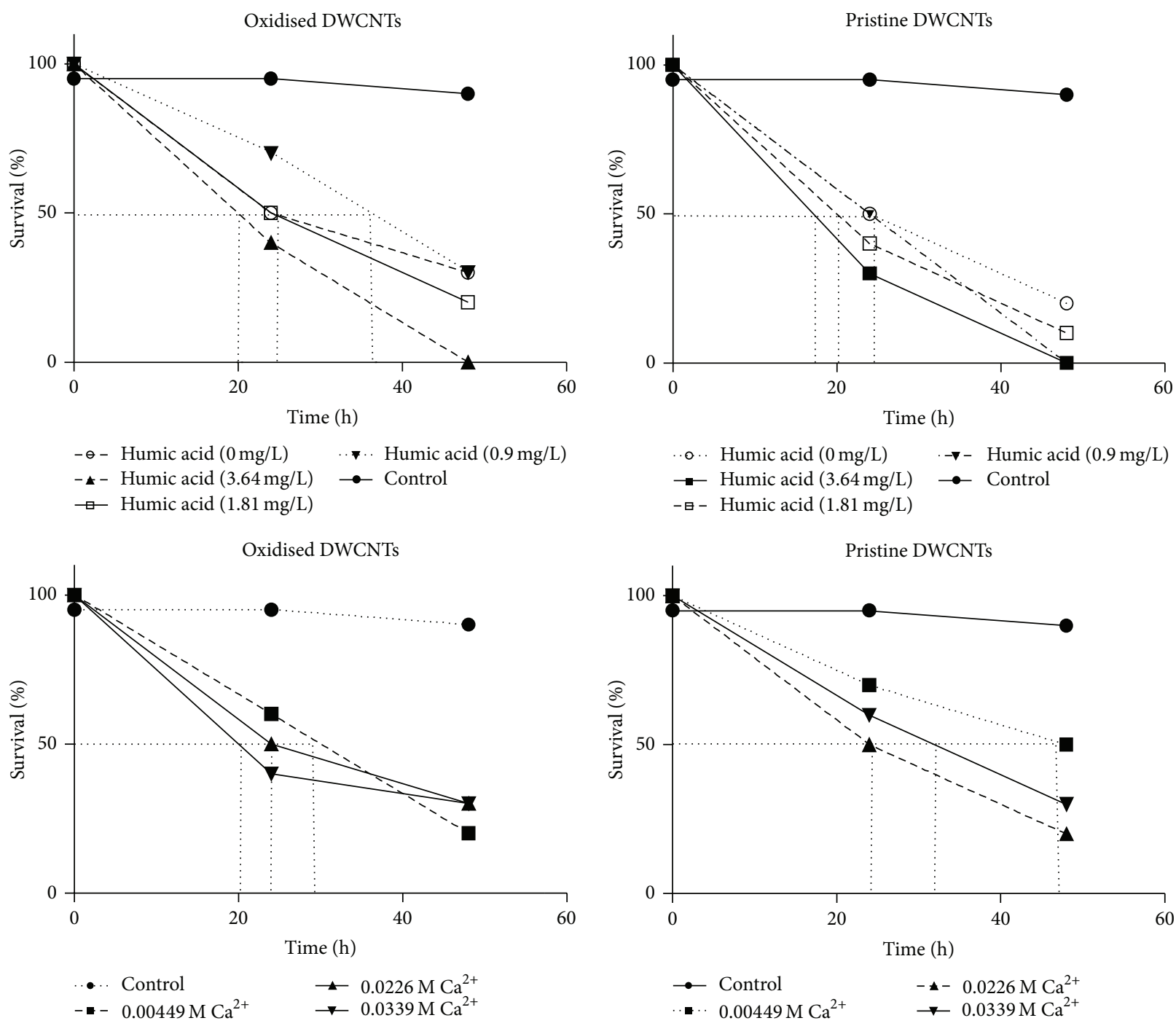

$\begin{array}{lll}\text {-.. Control } & \rightarrow 0.0226 \mathrm{M} \mathrm{Ca}^{2+} \\ -- & 0.00449 \mathrm{M} \mathrm{Ca}^{2+} \rightarrow 0.0339 \mathrm{M} \mathrm{Ca}^{2+}\end{array}$

Oxidised DWCNTs

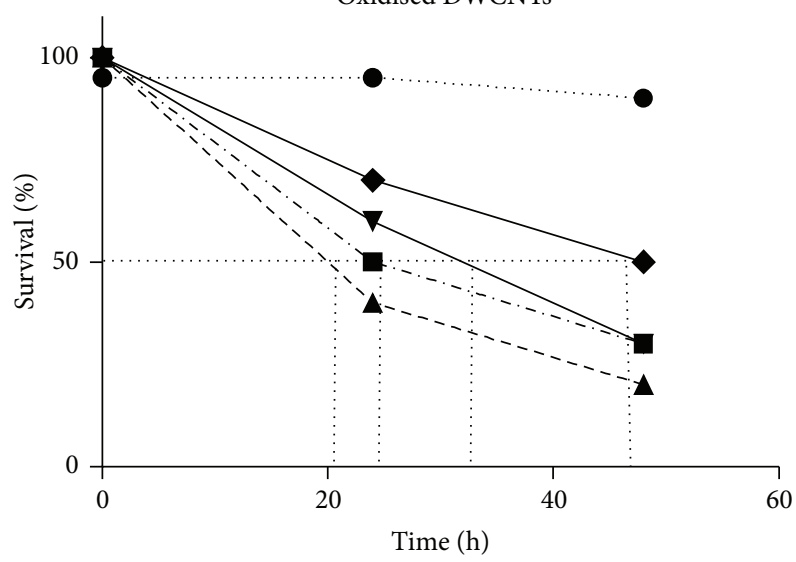

. o. Humic acid $(0 \mathrm{mg} / \mathrm{L}) \quad \rightarrow-$ Humic acid $(0.9 \mathrm{mg} / \mathrm{L})$

- Humic acid $(3.64 \mathrm{mg} / \mathrm{L}) \rightarrow$ Control

- - Humic acid $(1.81 \mathrm{mg} / \mathrm{L})$

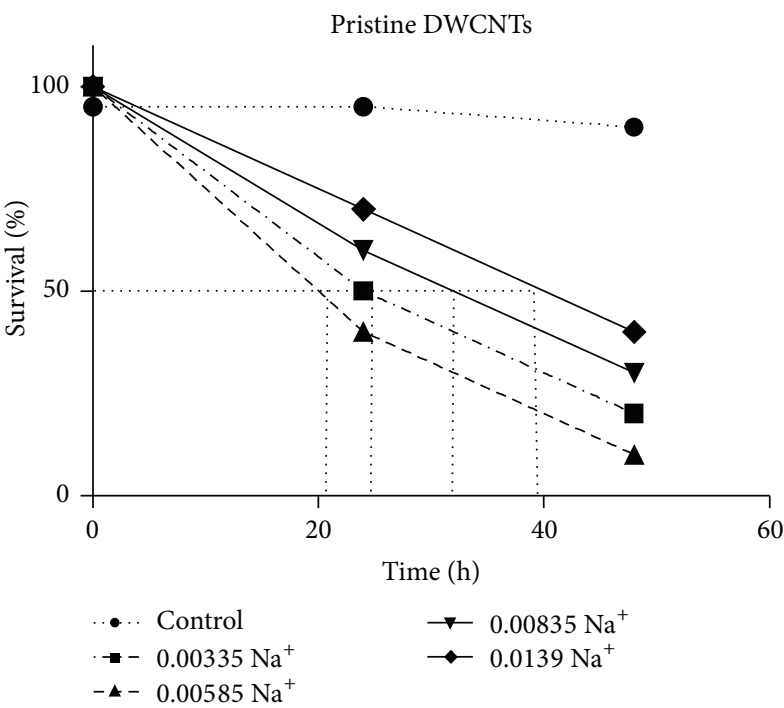

-.. Control

$\rightarrow 0.00835 \mathrm{Na}^{+}$

- $0.00335 \mathrm{Na}^{+}$

$\rightarrow 0.0139 \mathrm{Na}^{+}$

- $-0.00335 \mathrm{Na}$

- $0.0139 \mathrm{Na}^{+}$

Figure 12: Survival of D. pulex at set time intervals for the different exposure conditions. 

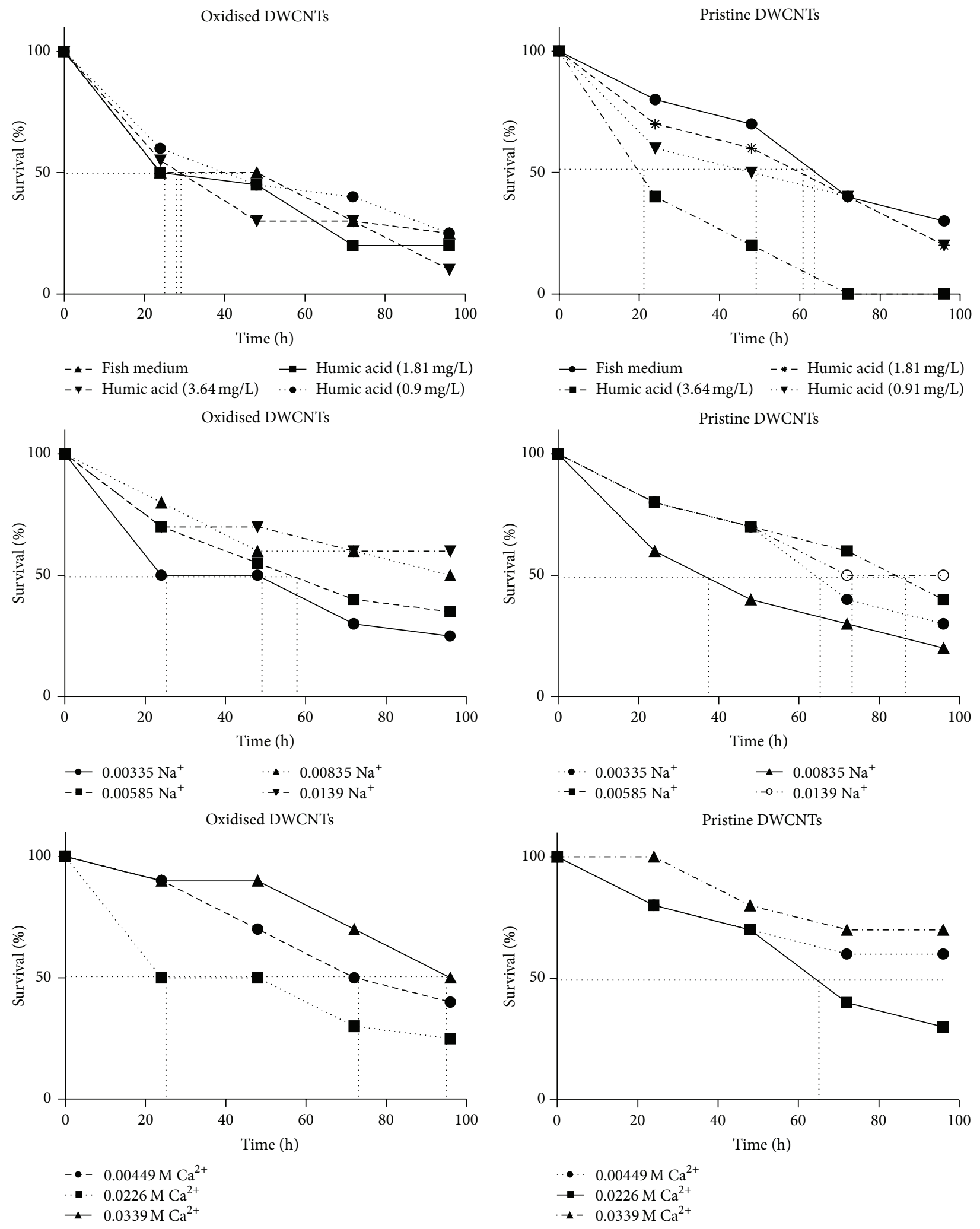

FIgURE 13: Survival of $P$. reticulata at set time intervals for the different exposure conditions. 

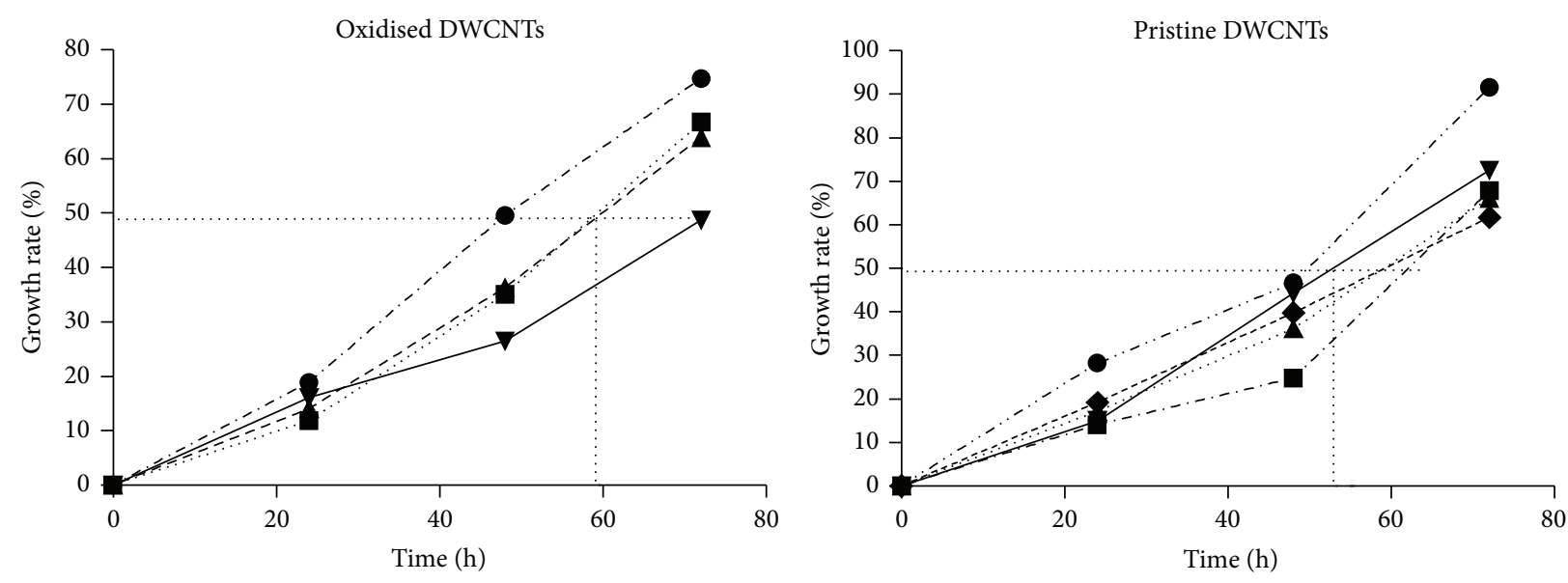

$\begin{array}{ll}- \text { - Algal medium } & - \text { Humic acid }(1.81 \mathrm{mg} / \mathrm{L}) \\ - & \text { Humic acid }(3.64 \mathrm{mg} / \mathrm{L}) \rightarrow \text { Humic acid }(0.91 \mathrm{mg} / \mathrm{L})\end{array}$
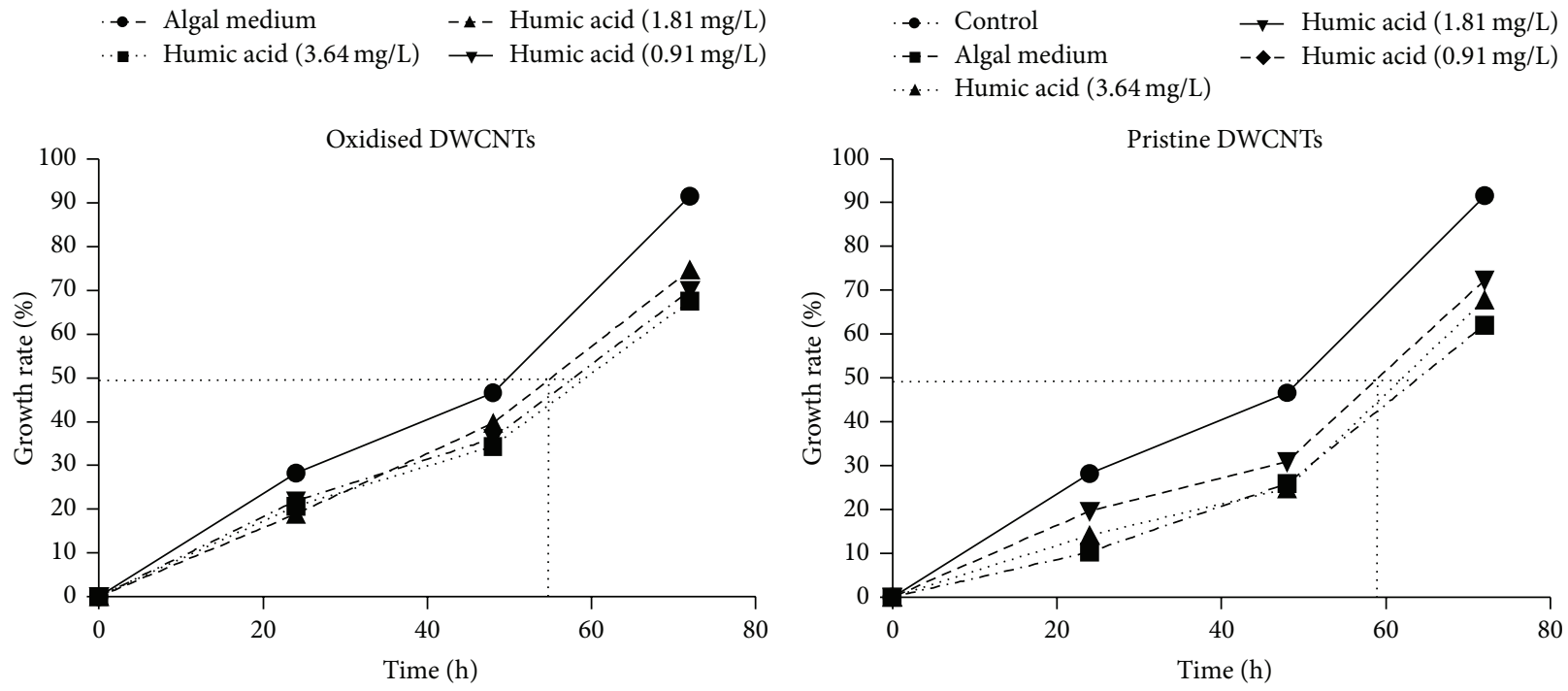

- Control $\quad-\$-0.0226 \mathrm{M} \mathrm{Ca}^{2+}$

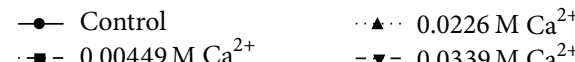
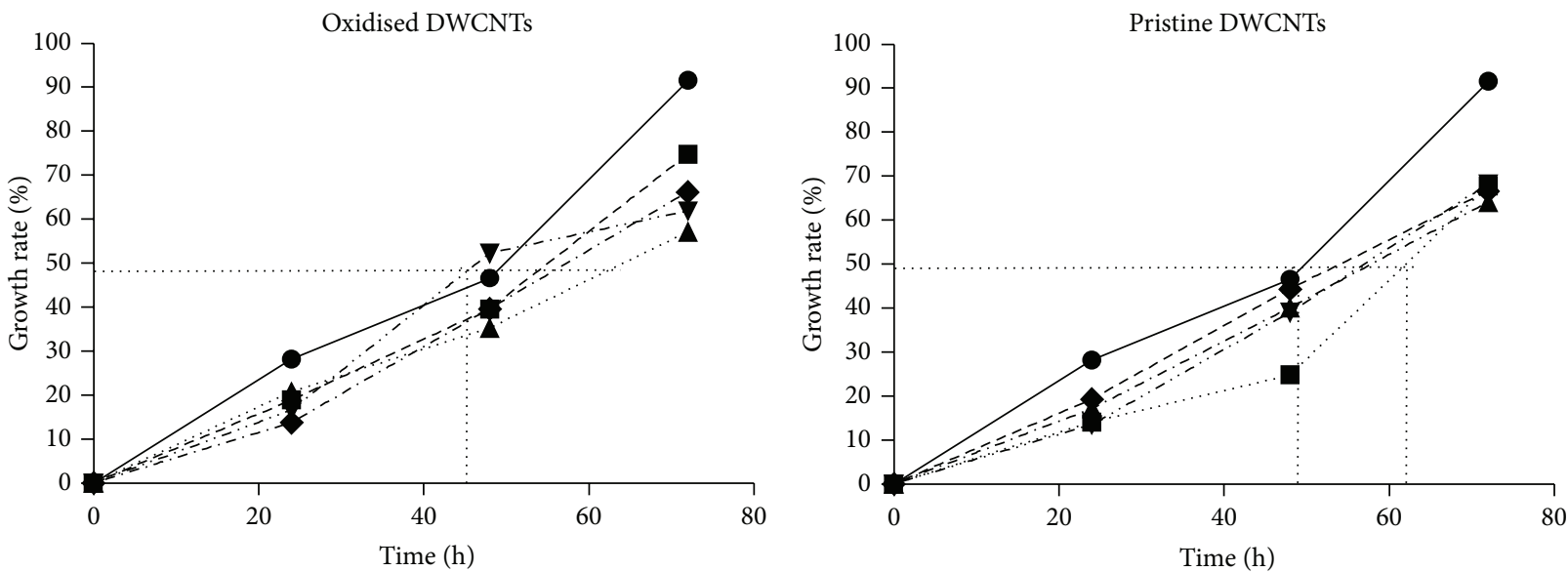

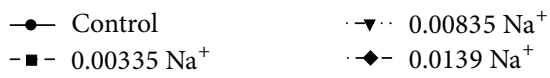

. . $0.00585 \mathrm{Na}^{+}$

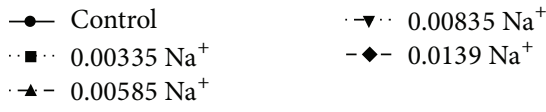

Figure 14: Growth rate P. subcapitata at set time intervals for the different exposure conditions. 
entangled with mucus strands leading to their interaction with cells [55]. Elemental analysis using EDX revealed that DWCNTs contained residual molybdenum catalyst and it could be argued that toxicity of DWCNTs is partly due to residual metal catalysis. However, these metal particles are normally embedded within the tube or particle and their removal using harsh acid treatment is difficult $[44,47,48,59]$. In such situations, the probability for metal catalysts leaching into exposure medium is quite low. Bennett and coworkers reported that less than $1 \%$ of metal residue leached from purified SWCNTs and the leached metals had no effect on the toxicity of SWCNTs to aquatic organisms [45].

The inverse was observed in the case of increased ionic strengths where $\mathrm{LC}_{50} \mathrm{~s}$ were found to be higher than $500 \mathrm{mg} / \mathrm{L}$. This is because DWCNTs in these conditions formed larger aggregates that settled at the bottom of the flask and $P$. reticulata ingested fewer suspended DWCNTs or the gill surfaces were not in contact with the DWCNTs.

3.8. Time-Based Acute Toxicity of DWCNTs to D. pulex, P. reticulata, and $P$. subcapitata. Acute toxicity can also be expressed using cumulative mortalities/survival plotted over time. These plots often illustrate whether a toxicant is toxic to part of the population within a certain period during the exposure experiment or whether mortality occurs at different rates within the exposure period.

The cumulative survival of $D$. pulex within each exposure experiment under the various conditions is shown in Figure 12 .

At the beginning of the exposures, the percentage survival of $D$. pulex population within each test was $100 \%$. The highest humic acid concentration resulted in a decrease in percentage survival of $50 \%\left(\mathrm{LC}_{50}\right)$ in $18 \mathrm{~h}$ and $20 \mathrm{~h}$ for both pristine and oxidised DWCNTs, respectively, and both reached $0 \%$ by the end of $48 \mathrm{~h}$. In the ionic strength treatments, the $0.0339 \mathrm{M} \mathrm{Ca}^{2+}$ and $0.0226 \mathrm{M} \mathrm{Ca}^{2+}$ treatments resulted in a percentage survival of $50 \%$ in $20 \mathrm{~h}$ and $24 \mathrm{~h}$, respectively, for oxidised DWCNTs while for pristine DWCNTs, the $0.0226 \mathrm{M}$ $\mathrm{Ca}^{2+}$ treatment, 50\% survival was reached in $24 \mathrm{~h}$. For all the treatments, the toxicity of DWCNTs did not cease after the initial die-off.

The $P$. reticulata negative control had a $100 \%$ survival for the first $72 \mathrm{~h}$ and at the end of exposure experiments, the percentage survival was at 95\% (Figure 13). The highest humic acid concentration $(3.64 \mathrm{mg} / \mathrm{L})$ resulted in a decrease in percentage survival of $50 \%\left(\mathrm{LC}_{50}\right)$ in $21 \mathrm{~h}$ for both pristine DWCNTs and all oxidised DWCNTs humic acid treatments reached $50 \%$ survival within $30 \mathrm{~h}$. In the ionic strength treatments, the $0.0226 \mathrm{M} \mathrm{Ca}^{2+}$ treatments resulted in a percentage survival of $50 \%$ in $24 \mathrm{~h}$ while the rest of the ionic treatments took longer to reach $50 \%$ mortalities.

The algal growth rates for all treatments and negative control reached $50 \%$ after $40 \mathrm{~h}$ (Figure 14). For both pristine and oxidised DWCNTs, the lowest growth rate was observed at a humic acid concentration of $0.9 \mathrm{mg} / \mathrm{L}$ while growth rates comparable to that of the negative control were observed at the highest humic acid concentration. The ionic strength of $0.00449 \mathrm{M} \mathrm{Ca}^{2+}$ treatment produced $50 \%$ growth rates between $50 \mathrm{~h}$ and $60 \mathrm{~h}$ for both pristine and oxidised DWCNTs. The $0.00335 \mathrm{M} \mathrm{Na}^{+}$ionic strength treatment showed the lowest growth rate reaching the $50 \%$ growth rate mark at $62 \mathrm{~h}$. The growth rates observed during all other treatments were similar to that of the negative control. Over prolonged exposure to SWCNTs, $P$. subcapitata growth rates decreased and later recovered [42]. However, the concentrations of SWCNTs were below $1 \mathrm{mg} / \mathrm{L}$.

Time-response acute toxicity plots are essential in highlighting the effect of a particular toxicant over the set period of exposure. These plots, however, are not common in nanoecotoxicity tests. The time-response plots for the three organisms show that toxicity of DWCNTs proceeds at varying rates throughout the exposure periods. None of the plots showed point of inflection which further illustrates that DWCNTs are not just toxic to that part of the test population that was exposed.

\section{Conclusion}

The toxicity of DWCNTs to the three organisms was found to be significantly different, with $D$. pulex being the most sensitive followed by $P$. subcapitata and $P$. reticulata being the least sensitive. The multitrophic approach provides information on the potential impact of DWCNTs on aquatic environments at concentrations ranging from 2 to $500 \mathrm{mg} / \mathrm{L}$. The mode of interaction of DWCNTs and organisms was found to play a significant role in the toxicity of DWCNTs. The agglomeration of double-walled carbon nanotubes entrapped $P$. subcapitata cells and deprived the cells of light. The light deprivation resulted in growth inhibition of the algal cells. In D. pulex and $P$. reticulata, the DWCNTs interacted with these organisms via their gut tracts. Humic acid increased the toxicity of DWCNTs to D. pulex and P. reticulata while increased ionic strength reduced the toxicity of DWCNTs to these organisms. Both humic acid and increased ionic strength reduced the toxicity of DWCNTs in P. subcapitata. The effect of the abovementioned parameters was found to be a direct consequence of their impact in the aggregation state of DWCNTs. The toxicity of DWCNTs proceeded at varying rates throughout the exposure periods for all organisms. There were no abrupt die-offs observed at the initial stages of exposure for all three organisms.

\section{Conflict of Interests}

The authors declare that there is no conflict of interests regarding the publication of this paper.

\section{References}

[1] A. Aqel, K. M. M. A. El-Nour, R. A. A. Ammar, and A. AlWarthan, "Carbon nanotubes, science and technology part (I) structure, synthesis and characterisation," Arabian Journal of Chemistry, vol. 5, no. 1, pp. 1-23, 2012.

[2] S. Osswald, E. Flahaut, H. Ye, and Y. Gogotsi, "Elimination of D-band in Raman spectra of double-wall carbon nanotubes by oxidation," Chemical Physics Letters, vol. 402, no. 4-6, pp. 422427, 2005. 
[3] J. N. Coleman, U. Khan, W. J. Blau, and Y. K. Gun’ko, "Small but strong: a review of the mechanical properties of carbon nanotube-polymer composites," Carbon, vol. 44, no. 9, pp. 1624$1652,2006$.

[4] K. W. Kwok, K. M. Leung, E. Flahaut, J. Cheng, and S. H. Cheng, "Chronic toxicity of double-walled carbon nanotubes to three marine organisms: influence of different dispersion methods," Nanomedicine, vol. 5, no. 6, pp. 951-961, 2010.

[5] N. Musee, "Nanowastes and the environment: potential new waste management paradigm," Environment International, vol. 37, no. 1, pp. 112-128, 2011.

[6] E. Flahaut, C. Laurent, and A. Peigney, "Catalytic CVD synthesis of double and triple-walled carbon nanotubes by the control of the catalyst preparation," Carbon, vol. 43, no. 2, pp. 375-383, 2005.

[7] V. Stone, B. Nowack, A. Baun et al., "Nanomaterials for environmental studies: classification, reference material issues, and strategies for physico-chemical characterisation," Science of the Total Environment, vol. 408, no. 7, pp. 1745-1754, 2010.

[8] A. Fairbrother and J. R. Fairbrother, "Are environmental regulations keeping up with innovation? A case study of the nanotechnology industry," Ecotoxicology and Environmental Safety, vol. 72, no. 5, pp. 1327-1330, 2009.

[9] M. C. Roco, B. Harthorn, D. Guston, and P. Shapira, "Innovative and responsible governance of nanotechnology for societal development," Journal of Nanoparticle Research, vol. 13, no. 9, pp. 3557-3590, 2011.

[10] R. D. Handy, G. Cornelis, T. Fernandes et al., "Ecotoxicity test methods for engineered nanomaterials: practical experiences and recommendations from the bench," Environmental Toxicology and Chemistry, vol. 31, no. 1, pp. 15-31, 2012.

[11] M. Crane, R. D. Handy, J. Garrod, and R. Owen, "Ecotoxicity test methods and environmental hazard assessment for engineered nanoparticles," Ecotoxicology, vol. 17, no. 5, pp. 421-437, 2008.

[12] K. Aschberger, C. Micheletti, B. Sokull-Klüttgen, and F. M. Christensen, "Analysis of currently available data for characterising the risk of engineered nanomaterials to the environment and human health-lessons learned from four case studies," Environment International, vol. 37, no. 6, pp. 1143-1156, 2011.

[13] R. A. Becker, L. M. Plunkett, J. F. Borzelleca, and A. M. Kaplan, "Tiered toxicity testing: evaluation of toxicity-based decision triggers for human health hazard characterization," Food and Chemical Toxicology, vol. 45, no. 12, pp. 2454-2469, 2007.

[14] S. L. Harper, J. L. Carriere, J. M. Miller, J. E. Hutchison, B. L. S. Maddux, and R. L. Tanguay, "Systematic evaluation of nanomaterial toxicity: utility of standardized materials and rapid assays," ACS Nano, vol. 5, no. 6, pp. 4688-4697, 2011.

[15] M. Farré, K. Gajda-Schrantz, L. Kantiani, and D. Barceló, "Ecotoxicity and analysis of nanomaterials in the aquatic environment," Analytical and Bioanalytical Chemistry, vol. 393, no. 1, pp. 81-95, 2009.

[16] B. Orthen, Nanotechnology: Health and Environmental Risks of Nanomaterials-Research Strategy, Bundesanstalt für Arbeitsschutz und Arbeitsmedizin (BAuA), Dortmund, Germany, 2007.

[17] I. Blinova, A. Ivask, M. Heinlaan, M. Mortimer, and A. Kahru, "Ecotoxicity of nanoparticles of $\mathrm{CuO}$ and $\mathrm{ZnO}$ in natural water," Environmental Pollution, vol. 158, no. 1, pp. 41-47, 2010.

[18] A. Baun, N. B. Hartmann, K. Grieger, and K. O. Kusk, "Ecotoxicity of engineered nanoparticles to aquatic invertebrates: a brief review and recommendations for future toxicity testing," Ecotoxicology, vol. 17, no. 5, pp. 387-395, 2008.
[19] J. I. E. Gao, S. Youn, A. Hovsepyan et al., "Dispersion and toxicity of selected manufactured nanomaterials in natural river water samples: effects of water chemical composition," Environmental Science \& Technology, vol. 43, no. 9, pp. 33223328, 2009.

[20] K. van Hoecke, K. A. C. de Schamphelaere, P. van der Meeren, S. Lucas, and C. R. Janssen, "Ecotoxicity of silica nanoparticles to the green alga Pseudokirchneriella subcapitata: importance of surface area," Environmental Toxicology and Chemistry, vol. 27, no. 9, pp. 1948-1957, 2008.

[21] B. J. Shaw and R. D. Handy, "Physiological effects of nanoparticles on fish: a comparison of nanometals versus metal ions," Environment International, vol. 37, no. 6, pp. 1083-1097, 2011.

[22] OECD, OECD Guidelines for the Testing of Chemicals 201: Freshwater Alga and Cyanobacteria, Growth Inhibition Test, 2002.

[23] OECD, OECD Guidelines for the Testing of Chemicals 202: Daphnia sp., Acute Immobilisation Test and Reproduction Test, OECD, 2004.

[24] OECD, "203: fish, acute toxicity test," in OECD Guidelines for Testing of Chemicals, pp. 1-10, 2002.

[25] United States Environmental Protection Agency (USEPA), Probit Program. Version 1.5, Ecological Monitoring Research Division, Environmental Monitoring Systems Laboratory, 1991.

[26] M. A. Hamilton, R. C. Russo, and R. V. Thurston, "Trimmed Spearman Karber method for estimating median lethal concentrations in toxicity bioassays," Environmental Science \& Technology, vol. 11, no. 7, pp. 714-719, 1977.

[27] APHA, Standard Methods for the Examination of Water and Wastewater, American Public Health Association (APHA), Washington, DC, USA, 1992.

[28] C. Desai, S. A. Ntim, and S. Mitra, "Antisolvent precipitation of hydrophobic functionalized multiwall carbon nanotubes in an aqueous environment," Journal of Colloid and Interface Science, vol. 368, no. 1, pp. 115-120, 2012.

[29] B. Smith, K. Wepasnick, K. E. Schrote et al., "Colloidal properties of aqueous suspensions of acid-treated, multi-walled carbon nanotubes," Environmental Science and Technology, vol. 43, no. 3, pp. 819-825, 2009.

[30] R. Barrena, E. Casals, J. Colón, X. Font, A. Sánchez, and V. Puntes, "Evaluation of the ecotoxicity of model nanoparticles," Chemosphere, vol. 75, no. 7, pp. 850-857, 2009.

[31] A. Schierz and H. Zänker, "Aqueous suspensions of carbon nanotubes: surface oxidation, colloidal stability and uranium sorption," Environmental Pollution, vol. 157, no. 4, pp. 10881094, 2009.

[32] I. Schwyzer, R. Kaegi, L. Sigg, R. Smajda, A. Magrez, and B. Nowack, "Long-term colloidal stability of 10 carbon nanotube types in the absence/presence of humic acid and calcium," Environmental Pollution, vol. 169, pp. 64-73, 2012.

[33] I. Schwyzer, R. Kaegi, L. Sigg, and B. Nowack, "Colloidal stability of suspended and agglomerate structures of settled carbon nanotubes in different aqueous matrices," Water Research, vol. 47, no. 12, pp. 3910-3920, 2013.

[34] M. M. Alloy and A. P. Roberts, "Effects of suspended multiwalled carbon nanotubes on daphnid growth and reproduction," Ecotoxicology and Environmental Safety, vol. 74, no. 7, pp. 1839-1843, 2011.

[35] H. Hyung and J.-H. Kim, "Natural organic matter (NOM) adsorption to multi-walled carbon nanotubes: effect of NOM characteristics and water quality parameters," Environmental Science and Technology, vol. 42, no. 12, pp. 4416-4421, 2008. 
[36] X. Ren, C. Chen, M. Nagatsu, and X. Wang, "Carbon nanotubes as adsorbents in environmental pollution management: a review," Chemical Engineering Journal, vol. 170, no. 2-3, pp. 395-410, 2011.

[37] N. B. Saleh, L. D. Pfefferle, and M. Elimelech, "Influence of biomacromolecules and humic acid on the aggregation kinetics of single-walled carbon nanotubes," Environmental Science \& Technology, vol. 44, no. 7, pp. 2412-2418, 2010.

[38] X. Wang, L. Shu, Y. Wang et al., "Sorption of peat humic acids to multi-walled carbon nanotubes," Environmental Science and Technology, vol. 45, no. 21, pp. 9276-9283, 2011.

[39] D. Lin and B. Xing, "Tannic acid adsorption and its role for stabilizing carbon nanotube suspensions," Environmental Science and Technology, vol. 42, no. 16, pp. 5917-5923, 2008.

[40] I. Schwyzer, R. Kaegi, L. Sigg, A. Magrez, and B. Nowack, "Influence of the initial state of carbon nanotubes on their colloidal stability under natural conditions," Environmental Pollution, vol. 159, no. 6, pp. 1641-1648, 2011.

[41] V. Datsyuk, P. Landois, J. Fitremann et al., "Double-walled carbon nanotube dispersion via surfactant substitution," Journal of Materials Chemistry, vol. 19, no. 18, pp. 2729-2736, 2009.

[42] S. Youn, R. Wang, J. Gao et al., "Mitigation of the impact of single-walled carbon nanotubes on a freshwater green algae: Pseudokirchneriella subcapitata," Nanotoxicology, vol. 6, no. 2, pp. 161-172, 2012.

[43] Z. Long, J. Ji, K. Yang, D. Lin, and F. Wu, "Systematic and quantitative investigation of the mechanism of carbon nanotubes' toxicity toward algae," Environmental Science \& Technology, vol. 46, no. 15, pp. 8458-8466, 2012.

[44] F. Schwab, T. D. Bucheli, L. P. Lukhele et al., "Are carbon nanotube effects on green algae caused by shading and agglomeration?" Environmental Science \& Technology, vol. 45, no. 14, pp. 6136-6144, 2011.

[45] S. W. Bennett, A. Adeleye, Z. Ji, and A. A. Keller, "Stability, metal leaching, photoactivity and toxicity in freshwater systems of commercial single wall carbon nanotubes," Water Research, vol. 47, no. 12, pp. 4074-4085, 2013.

[46] L. Wei, M. Thakkar, Y. Chen, S. A. Ntim, S. Mitra, and X. Zhang, "Cytotoxicity effects of water dispersible oxidized multiwalled carbon nanotubes on marine alga, Dunaliella tertiolecta," Aquatic Toxicology, vol. 100, no. 2, pp. 194-201, 2010.

[47] X. Zhu, L. Zhu, Y. Chen, and S. Tian, "Acute toxicities of six manufactured nanomaterial suspensions to Daphnia magna," Journal of Nanoparticle Research, vol. 11, no. 1, pp. 67-75, 2009.

[48] A. J. Kennedy, M. S. Hull, J. A. Steevens et al., "Factors influencing the partitioning and toxicity of nanotubes in the aquatic environment," Environmental Toxicology and Chemistry, vol. 27, no. 9, pp. 1932-1941, 2008.

[49] A. J. Edgington, A. P. Roberts, L. M. Taylor et al., "The influence of natural organic matter on the toxicity of multiwalled carbon nanotubes," Environmental Toxicology and Chemistry, vol. 29, no. 11, pp. 2511-2518, 2010.

[50] E. J. Petersen, J. Akkanen, J. V. K. Kukkonen, and W. J. Weber Jr., "Biological uptake and depuration of carbon nanotubes by Daphnia magna," Environmental Science and Technology, vol. 43, no. 8, pp. 2969-2975, 2009.

[51] A. Feswick, R. J. Griffitt, K. Siebein, and D. S. Barber, "Uptake, retention and internalization of quantum dots in Daphnia is influenced by particle surface functionalization," Aquatic Toxicology, vol. 130-131, pp. 210-218, 2013.
[52] R. D. Handy, T. B. Henry, T. M. Scown, B. D. Johnston, and C. R. Tyler, "Manufactured nanoparticles: their uptake and effects on fish-a mechanistic analysis," Ecotoxicology, vol. 17, no. 5, pp. 396-409, 2008.

[53] R. D. Handy, F. von der Kammer, J. R. Lead, M. Hassellöv, R. Owen, and M. Crane, "The ecotoxicology and chemistry of manufactured nanoparticles," Ecotoxicology, vol. 17, no. 4, pp. 287-314, 2008.

[54] A. A. Sharbidre, V. Metkari, and P. Patode, "Effect of methyl parathion and chlorpyrifos on certain biomarkers in various tissues of guppy fish, Poecilia reticulata," Pesticide Biochemistry and Physiology, vol. 101, no. 2, pp. 132-141, 2011.

[55] C. J. Smith, B. J. Shaw, and R. D. Handy, "Toxicity of single walled carbon nanotubes to rainbow trout, (Oncorhynchus mykiss): respiratory toxicity, organ pathologies, and other physiological effects," Aquatic Toxicology, vol. 82, no. 2, pp. 94-109, 2007.

[56] S. J. Klaine, P. J. J. Alvarez, G. E. Batley et al., "Nanomaterials in the environment: behavior, fate, bioavailability, and effects," Environmental Toxicology and Chemistry, vol. 27, no. 9, pp. 18251851, 2008.

[57] P.-H. Chen, K.-M. Hsiao, and C.-C. Chou, "Molecular characterization of toxicity mechanism of single-walled carbon nanotubes," Biomaterials, vol. 34, no. 22, pp. 5661-5669, 2013.

[58] H. Hyung, J. D. Fortner, J. B. Hughes, and J.-H. Kim, "Natural organic matter stabilizes carbon nanotubes in the aqueous phase," Environmental Science and Technology, vol. 41, no. 1, pp. 179-184, 2007.

[59] J.-F. Colomer, L. Henrard, E. Flahaut, G. van Tendeloo, A. A. Lucas, and P. Lambin, "Rings of double-walled carbon nanotube bundles," Nano Letters, vol. 3, no. 5, pp. 685-689, 2003. 

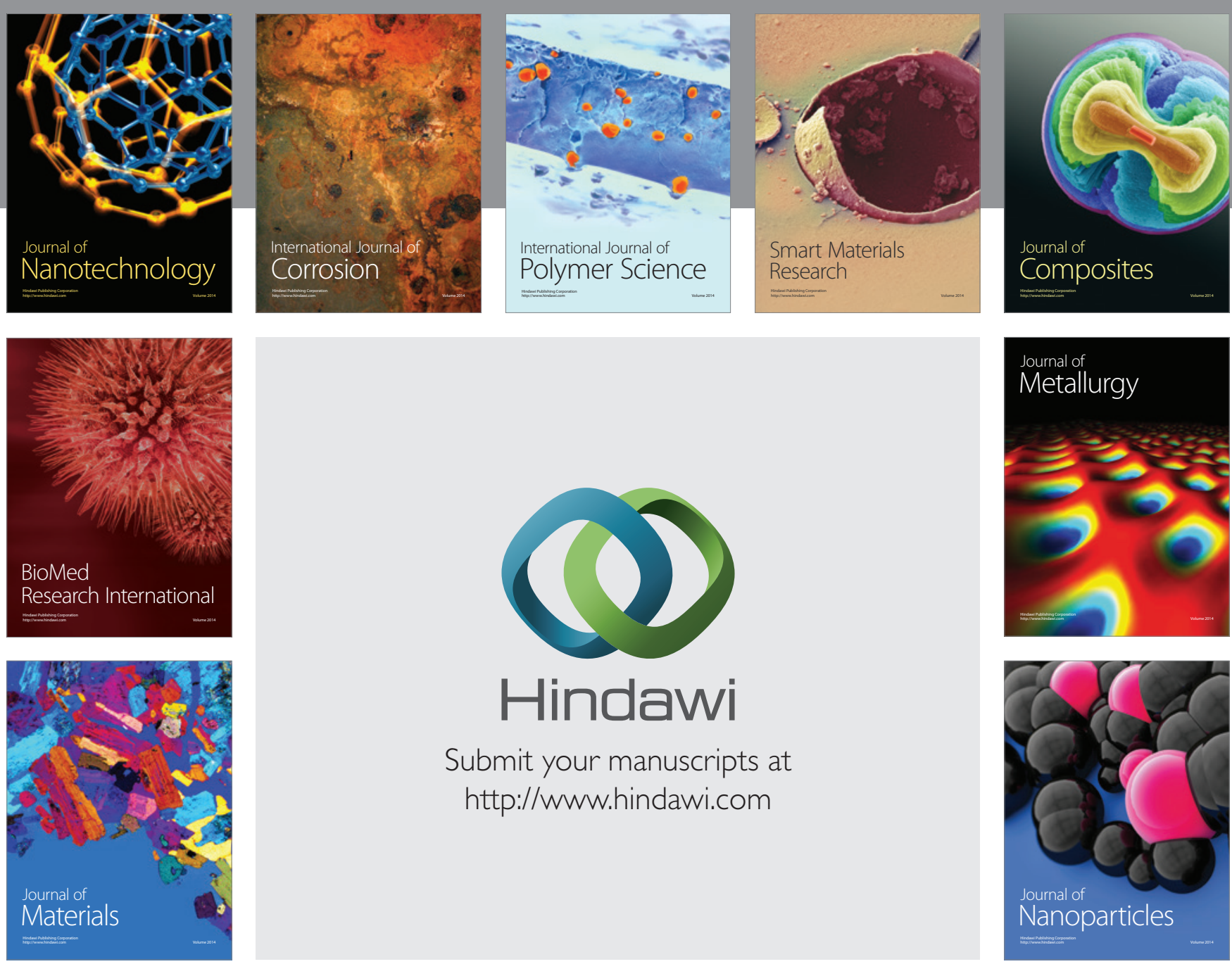

Submit your manuscripts at http://www.hindawi.com
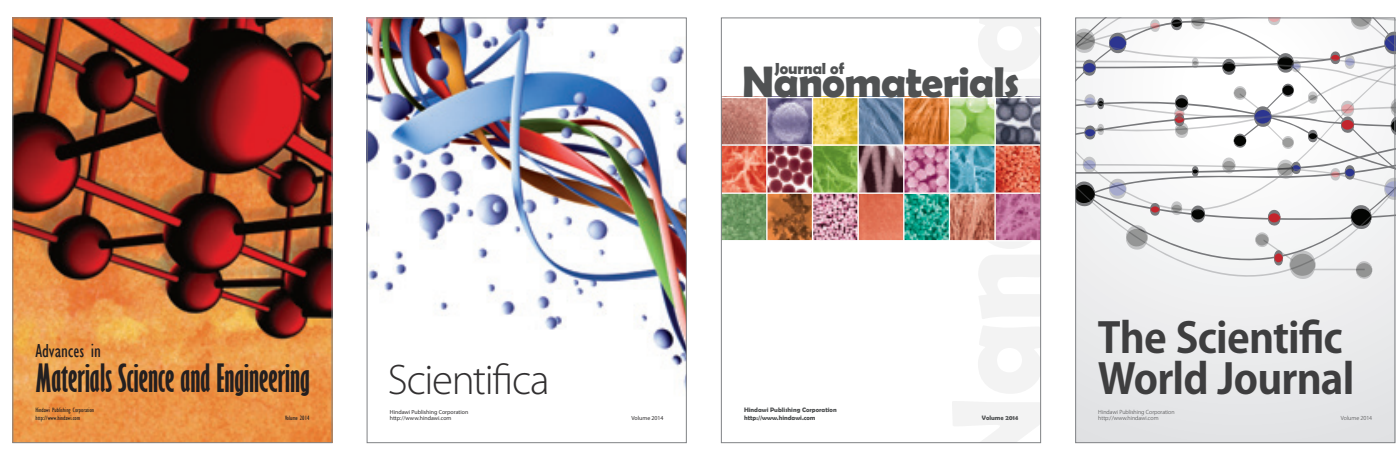

\section{The Scientific World Journal}
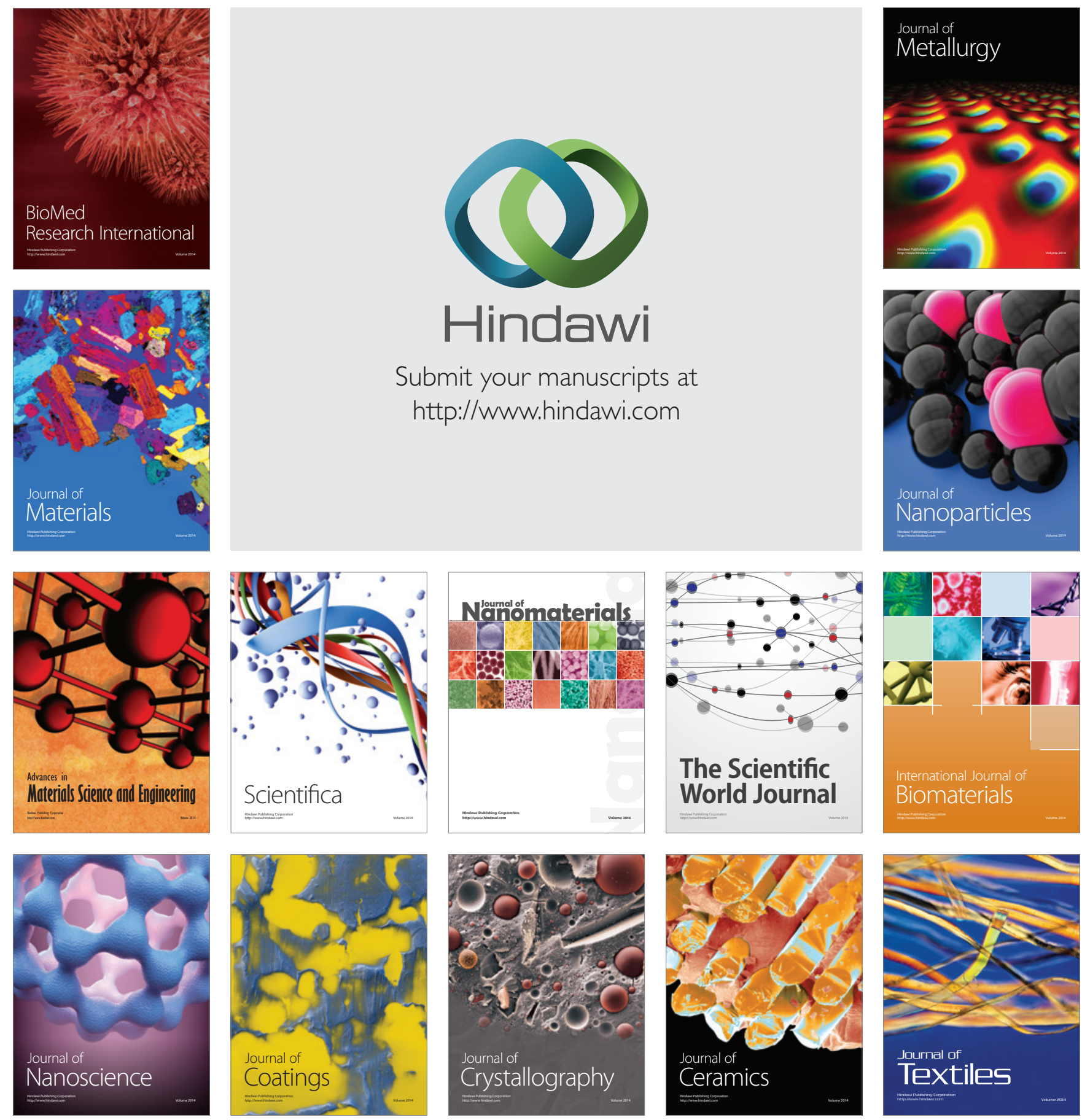